\title{
Air Space Distension Precedes Spontaneous Fibrotic Remodeling and Impaired Cholesterol Metabolism in the Absence of Surfactant Protein C
}

\author{
Jannik Ruwisch ${ }^{1,2^{*},}$ Kirsten Sehlmeyer ${ }^{1,2^{*}}$, Nuria Roldan ${ }^{3,4}$, Begoña Garcia-Alvarez ${ }^{4}$, Jesus Perez-Gil ${ }^{4}$, \\ Timothy E. Weaver ${ }^{5}$, Matthias Ochs ${ }^{1,2,6}$, Lars Knudsen ${ }^{1,2}$ and Elena Lopez-Rodriguez ${ }^{1,2,6 \#}$ \\ ${ }^{1}$ Institute of Functional and Applied Anatomy, Hannover Medical School, Hannover, Germany \\ ${ }^{2}$ Biomedical Research in Endstage and Obstructive Lung Disease Hannover (BREATH), Member of \\ the German Centre for Lung Research (DZL), Hannover, Germany \\ ${ }^{3}$ Alveolix AG and ARTORG Center, University of Bern, Bern, Switzerland \\ ${ }^{4}$ Biochemistry and Molecular Biology Department, Faculty of Biology, and Research Institute \\ “Hospital 12 de Octubre”, Complutense University Madrid, Madrid, Spain \\ ${ }^{5}$ Cincinnati Children's Hospital Medical Center and the University of Cincinnati College of \\ Medicine, Cincinnati, Ohio \\ ${ }^{6}$ Institute of Vegetative Anatomy, Charité - Universitaetsmedizin Berlin, Berlin, Germany \\ *both authors contributed equally to this work \\ \# Correspondence: elena.lopez-rodriguez@charite.de, Charite Universitatsmedizin zu Berlin, Institute of \\ Vegetative Anatomy, Philippstr. 12, 10115 Berlin, +49 30450528037
}

This article has an online data supplement, which is accessible from this issue's table of content online at www.atsjournals.org. 
Author Contributions: conceptualization, Lars Knudsen and Elena Lopez-Rodriguez; methodology, Jannik Ruwisch, Kirsten Sehlmeyer, Nuria Roldan and Elena Lopez-Rodriguez; formal analysis, Jannik Ruwisch, Kirsten Sehlmeyer, Nuria Roldan and Elena Lopez-Rodriguez; investigation, Jannik Ruwisch, Kirsten Sehlmeyer, Nuria Roldan and Elena Lopez-Rodriguez; writing - original draft preparation, Jannik Ruwisch, Kirsten Sehlmeyer, Nuria Roldan, Begoña Alvarez, Jesus Perez-Gil, Tim Weaver, Matthias Ochs, Lars Knudsen and Elena Lopez-Rodriguez; writing-review and editing, Jannik Ruwisch, Kirsten Sehlmeyer, Nuria Roldan, Begoña Alvarez, Jesus Perez-Gil, Tim Weaver, Matthias Ochs, Lars Knudsen and Elena Lopez-Rodriguez; supervision, Lars Knudsen and Elena Lopez-Rodriguez; project administration, Elena Lopez-Rodriguez; funding acquisition, Matthias Ochs, Lars Knudsen and Elena Lopez-Rodriguez. 


\section{Abstract:}

Surfactant protein C (SP-C) deficiency is found in samples from patients suffering idiopathic pulmonary fibrosis (IPF), especially in familial forms of this disease. We hypothesized that SP-C may contribute to fibrotic remodeling in aging mice and alveolar lipid homeostasis. For this purpose, we analyzed lung function, alveolar dynamics, lung structure, collagen content and expression of genes related to lipid and cholesterol metabolism of aging SP-C knock out mice. In addition, in vitro experiments with an alveolar macrophage cell line exposed to lipid vesicles with/without cholesterol and/or SP-C were performed. Alveolar dynamics showed progressive alveolar de-recruitment with age and impaired oxygen saturation. Lung structure revealed that decreasing volume density of alveolar spaces was accompanied by increasing of the ductal counterparts. Simultaneously, septal wall thickness steadily increased, and fibrotic wounds appeared in lungs from the age of 50 weeks. This remarkable phenotype is unique to the 129Sv strain, which has an increased absorption of cholesterol, linking the accumulation of cholesterol and the absence of SP-C to a fibrotic remodeling process. The findings of this study suggest that overall loss of SP-C results in an age-dependent complex, heterogeneous phenotype characterized by a combination of over distended air spaces and fibrotic wounds that resembles CEPF (Combined Emphysema and Pulmonary Fibrosis) in IPF human patients. Addition of SP-C to cholesterol-laden lipid vesicles enhanced the expression of cholesterol metabolism and transport genes in an alveolar macrophage cell line, identifying a potential new lipid-protein axis involved in lung remodeling.

Keywords: surfactant protein C, pulmonary fibrosis, alveolar dynamics, lung structure, alveolar homeostasis, lipid metabolism, alveolar macrophages 


\section{Introduction}

Idiopathic pulmonary fibrosis (IPF) is a chronic progredient, restrictive interstitial lung disease (ILD), characterized by increased collagen deposition with fatal outcome. Current pathogenetic concepts focus on the dysfunction of alveolar epithelial type 2 cells (AEC2), stem cell exhaustion and aberrant profibrotic wound repair (1). On high resolution computer tomography (HRCT) images, IPF depicts the picture of usual interstitial pneumonia (UIP), characterized by the presence of heterogeneously distributed honeycomb cysts with basal and subpleural predominance (2-4). $2-20 \%$ of IPF patients present with a positive familial history classified as familial pulmonary fibrosis (FPF) (5-8). Multiple gene studies have identified a wide set of genes that seem to drive fibrogenesis (9-12), including mutations of genes encoding surfactant proteins $(7,13-16)$.

Pulmonary surfactant mainly consists of phospholipids (PL) and surfactant proteins A, B, C and D. SP-B and SP-C are essential for reducing surface tension at the alveolar air-liquid interface $(17,18)$. The hydrophobic, mature SP-C peptide has been shown to be crucial for maintaining surfactant homeostasis under dynamic conditions. During surfactant film compression, SP-C provides film stability at low lung volumes $(17,19,20)$. As the respiratory cycle progresses, SP-C facilitates the re-incorporation of subinterfacial phospholipids into the monolayer, promoting film expansion upon inspiration $(17,18,21)$. To date more than 60 different mutations in the human SFTPC gene have been associated with development of acute and chronic lung disease in infants, children and adults (22-24). The SFTPC gene is exclusively expressed by AEC2 and encodes the 21kDa precursor protein proSP-C $(25,26)$.

Aging is one of the main common factors in IPF mainly affecting patients exceeding the age of 60 (2). With increasing age the lung is progressively challenged with harmful biological and physical noxae (2729). Multiple hits such as repeated exposure to mechanical stress, as occurs during heterogenous lung ventilation in the setting of increased surface tension and alveolar instability, were further shown to 
compromise AEC2 integrity (30-33). Aging lungs themselves show a trend towards increasing lung stiffness and lower compliance in combination with lower surfactant volumes that, in turn, may contribute to impaired lung function in the elderly $(34,35)$.

In addition, impaired lipid metabolism is related to many different lung diseases including pulmonary alveolar proteinosis (PAP) and lung fibrosis. Reduced lipid metabolism has been related to endoplasmic reticulum (ER) stress (36) and as communication axis between AE2C and alveolar macrophages (37) leading to fibrotic remodeling. Even though limited information in the exact mechanisms of regulation of lipid metabolism, and more specifically cholesterol metabolism, exits (38), it may present a new therapeutic target in lung fibrosis (39).

In the current study, we aim to elucidate the role of SP-C in the development of spontaneous lung fibrosis as well as the ordering of the events leading to fibrotic remodeling in the absence of this protein. For this, we studied the alveolar dynamics, lung structure and function of SP-C KO mice during 60 weeks of life, as well as the morphologic and metabolic changes experienced by alveolar macrophages with or without SP-C.

\section{Material and Methods}

\section{Animal model}

SP-C deficient mice, bred on the 129Sv background, were introduced before (40) and obtained with permission from Cincinnati children's hospital (Cincinnati, Ohio). 129Sv healthy mice, which served as control group, were acquired from Charles River GmbH (Sulzfeld, Germany). Details about the animal groups is stated in supplementary methods. 


\section{Lung mechanic and function measurements}

All animals were weighed and anesthetized via intraperitoneal injection of $80 \mathrm{mg} / \mathrm{kg}$ ketamine and $5 \mathrm{mg} / \mathrm{kg}$ xylazine in $0.9 \%$ sodium chloride. Following tracheotomy, mice were connected to a small animal ventilator (FlexiVent, SCIREQ, Montreal, QC, Canada). Mechanical ventilation was performed as described previously (41) and detailed in supplementary methods. Oxygen saturation in percentage of functional arterial hemoglobin was determined during normal mechanical ventilation at PEEP $3 \mathrm{cmH}_{2} \mathrm{O}$ with the use of a rodent oximeter (MouseOx Plus, Starr Life Sciences Corp., US). Afterwards vascular perfusion-fixation was performed as explained in supplementary methods.

\section{Histological sections and staining}

Tissue slices were embedded into hydroxyethylmethacrylate (Technovit 8100, Kulzer Heraeus, Wehrheim, Germany). For further design-based stereology on light microscope level, tissue sections were stained with toluidine blue as detailed in supplementary methods. Simultaneously, lung cubes were sampled randomly for representative electron microscope (EM) imaging as explained in supplementary methods. Remaining tissue slices were embedded in paraffin and stained with a Masson-Goldner staining kit (Merck, Darmstadt, Germany). Immunostaining of human tissue sections is detailed in supplementary methods.

\section{Design-based stereology}

Design-based stereology is the gold-standard for quantitative lung structure analysis based on histological images enabling profound mathematical inference from 2D sections about 3D geometrical bodies, as which microarchitectural compartments of the distal lung have to be considered (42). All analyzed parameters for lung structure regarding fibrosis were chosen according to recommendations from 
Ochs and Mühlfeld (43) for stereology in pulmonary fibrosis. A detailed description of investigated parameters and corresponding test systems is presented in table 1 and supplementary methods.

\section{Hydroxyproline assay}

Hydroxyproline content was measured in accordance to the protocol established by Reddy and Enwemeka (44) and detailed in supplementary methods.

\section{Real time - PCR}

RNA was isolated from homogenized, post-lavage lungs following ISOLATE II RNA Mini Kit instructions (ISOLATE RNA Mini Kit, Bioline $\mathrm{GmbH}$, Luckenwalde, Germany). cDNA synthesis was performed in a Thermal Cycler (CFX96TM, Bio-Rad Laboratories, Munich, Germany). Subsequent RT-PCR was performed with iTaq Universal SYBR Green Supermix (Bio-Rad Laboratories, Munich, Germany), primer sequences are shown in detail in table 2 and detailed in supplementary methods.

\section{Cholesterol assay}

Total cholesterol concentration was quantified following instructions of Total Cholesterol Assay Kit (Colorimetric) (Cell Biolabs, Inc., San Diego, CA 92126) as explained in supplementary methods.

\section{Engulfment of cholesterol-laden lipid vesicles with or without SP-C}

Uptake of cholesterol-laden with/without SP-C lipid vesicles by alveolar macrophages was performed using a fluorescently label cholesterol probe and quantified as the percentage of cells presenting fluorescence in a flow cytometer. Further details can be found in supplementary methods.

\section{Statistical analysis}

Graphs and statistical analysis were conducted with GraphPad Prism 6.0 (GraphPad Software, San Diego, CA, USA) and detailed in supplementary methods. 


\section{Results}

Impaired alveolar recruitment is accompanied by increased tissue stiffness in the lungs of SP-C KO mice

Body weight (BW) gain was significantly delayed in SP-C KO mice in comparison to healthy $129 \mathrm{~Sv}$ mice up to an age of 40 weeks (Figure 1A). Likewise, absolute lung volume was significantly reduced at early ages (10 and 20 weeks) (Figure 1B). Simultaneously, inspiratory capacity (IC) was significantly reduced at an age of 10 and 20 weeks in comparison to healthy mice (Figure 1C). Accordingly, static compliance (Cst) (Figure 1D) was significantly reduced in comparison to age-matched healthy 129Sv mice.

Tissue elastance $(\mathrm{H})$ was assessed at positive end-expiratory pressure (PEEP) of $1 \mathrm{cmH}_{2} \mathrm{O}, 3 \mathrm{cmH}_{2} \mathrm{O}$ and $6 \mathrm{cmH}_{2} \mathrm{O}$ as an indicator of distal parenchymal stiffness (Figure 1E). At the early age of 10 and 20 weeks, lungs of SP-C KO mice exhibited significantly increased tissue elastance compared to healthy controls at every applied PEEP (Figure 1F-H) pointing at stiffer lungs in the absence of SP-C at early ages. Increasing airway pressure from 1 to $6 \mathrm{cmH}_{2} \mathrm{O}$ may facilitate alveolar recruitment, resulting in reduced tissue stiffness, as seen in healthy $129 \mathrm{~Sv}$ mice (Suppl. Figure 1A). However, an applied PEEP of $6 \mathrm{cmH}_{2} \mathrm{O}$ (Figure 1E) failed to further reduce tissue elastance at the ages of 10, 50 and 60 weeks, compared to low pressure such as PEEP of $3 \mathrm{cmH}_{2} \mathrm{O}$ in the SP-C KO group. This pointed at reduced recruitability of alveolar spaces at older ages (either due to alveolar collapse, permanent de-recruitment and/or a remodeling process) as a result of SP-C deficiency during an abnormal lung aging. In addition, a mixed-effects statistical analysis revealed that changes were mostly an effect of both genotype and aging (Suppl. Table 3)

Accordingly, tissue damping $(\mathrm{G})$, assessed at PEEP of $3 \mathrm{cmH}_{2} \mathrm{O}$, significantly decreased from week 20 to week 30 in the SP-C KO group, while healthy mice showed no age-dependent alterations in G (Figure 1I). Meanwhile, tissue hysteresivity ( $\eta$ ) of SP-C KO mice exhibited only minor fluctuations in contrast to healthy controls displaying a continuous increase until 50 weeks of age (Figure 1J). Thus, significant 
differences between both groups were found at an age of 10 and 40 weeks, suggesting altered rheological properties of the lung tissue. However, the main effect was due to age and not genotype (Suppl. Table 3).

Stereological analysis revealed an increased volume fraction $(\mathrm{Vv})$ of non-ventilated parenchyma in the SP-C KO group in comparison to healthy mice, which was significant at an age of 20, 40, 50 and 60 weeks (Figure 1K). Taken together, deficiency of SP-C resulted in loss of ability on reopening alveoli at higher pressure and abnormal rheological properties of the lung tissue, pointing at an ongoing remodeling process. In addition, a mixed-effects statistical analysis revealed the absence of SP-C as major contributor to the decrease of ventilated parenchyma and the increase of non-ventilated parenchyma (Supp. Table 3)

\section{Ductal airspace overdistension precedes septal thickening in the SP-C KO lung}

General lung morphology during aging can be observed in figure 2A. SP-C KO lungs exhibited a slight age-dependent decrease in alveolar space volume fraction $(\mathrm{Vv}(\mathrm{alv} / \mathrm{par}))$ meanwhile an increase in ductal airspace volume fraction ( $\mathrm{Vv}($ duct/par), which became significant at 50 weeks of age (Figure 2B and 2C). Accordingly, mean linear intercept length measurements were not significantly changed in SP-C KO versus healthy 129Sv mice, except at 50 weeks of age (Figure 2D). Healthy 129Sv mice lungs did not reveal a major trend towards an increasing or decreasing $\mathrm{Vv}$ (alv/par) (Figure 2B). In addition, volume weighted mean volume $\left(\bar{v}_{\mathrm{v}}(\mathrm{alv})\right)$ values varied around the baseline observed at 10 weeks (Figure 2E) for healthy controls. In contrast, $\bar{v}_{\mathrm{v}}(\mathrm{alv})$ remained unaltered over the first 20 weeks in the SP-C KO group, but exhibited a significant increase at the end of week 30 (Figure 2E), indicating a rearrangement in the alveolar architecture and increased alveolar size heterogeneity.

Alveolar epithelial surface (S(alvepi)) was significantly reduced at 20 and 50 weeks in contrast to healthy mice (Figure 2F). In line with lung volume development, alveolar surface rose significantly in the lungs of 30-week-old SP-C KO animals, but tended to decline from week 30 to week 50 (Figure 2F). Simultaneously, septal thickness steadily decreased until week 40 , where a tendency towards thicker 
alveolar septa was observed (Figure 2G). Accordingly, SP-C KO mice lungs showed significantly thicker septal walls, in head-to-head comparison with their healthy counterparts at an age of 50 weeks (Figure 2G). Significantly, increased thickness from week 50, coincided with the appearance of consolidated lesions, giving the first indication of fibrotic remodeling (Figure 2A; micrographs 10 and 12). In addition, over distended ductal airspaces corresponding to increased ductal airspace volume fraction became particularly prominent in subpleural regions (Figure 2A; micrographs 3, 5 and 7). These features were not observed in healthy control lungs (Suppl. Figure 2A).

\section{SP-C KO mice lungs exhibit altered tissue composition and aberrant connective-tissue protein gene expression}

Masson's-Goldner trichrome staining provided further insight into tissue composition of observed microscopic wounds, most prominently in the lungs of 50 and 60 weeks of age. While thickness of septa was not accompanied by staining for collagen from week 10 to week 20, consolidations in parenchyma stained positive for collagen at the age of 50 and 60 weeks (green, Figure 3A), especially in comparison to older healthy mice (Suppl. Figure 3A). Therefore, increased septal thickness at early ages seemed to arise from alveolar collapse, while the later onset of thickening was associated with interstitial collagen deposition. Quantification of hydroxyproline showed a tendency towards higher levels with age but did not demonstrate significant differences between age cohorts or genotypes (Figure 3B and Suppl. Figure 3B). Relative Col1a1, Col3a1 and Fn expression obtained from RT-PCR analysis was significantly downregulated in the SP-C KO mice over age (Figures 3C, 3D and 3F). Likewise, Col2a1 and Eln also tended towards lower expression levels but were not significantly different (Figure 3F and 3G). This represents a different, aberrant remodeling of fibers in comparison with the normal re-distribution of fibers in healthy aging mice (Suppl. Figure 3C-3G). 


\section{SP-C deficiency alters the innate immune system of the lung}

The total number of cells in BAL of the SP-C KO cohort declined with age (Figure 4A). In contrast, the number of cells counted in healthy BAL remained constant at a generally lower level than in BAL recovered from SP-C KO mice (Figure 4A). Statistical analysis revealed significant differences between healthy and SP-C KO at 10 and 20 weeks of age and the effect seemed to be mainly due to the genotype and not age (Supp. Table 3). Light microscopic analysis of immune cell subtypes identified macrophages as the predominant cell type with a minor but constant fraction of neutrophils in the healthy mice independent of age (Figure 4B and Suppl. Figure 4A). In contrast, the proportion of neutrophils was increased in SP-C KO mice at 40 weeks of age and was accompanied by the appearance of eosinophils at week 50 .

Fibrotic areas of a lung section validated the presence of electron-dense clefts in IPF lung tissue (Figure 4C). Further, ultrastructural phenotype qualitative analysis of lung macrophages was performed in the SPC KO mice for every age group. At 10 and 20 weeks of age, macrophages derived from SP-C KO lungs exhibited numerous electron-dense, lamellar-body-like, inclusions in the cytoplasmic cell compartment. In the successive 10 weeks, the cells further accumulated these inclusions and appeared loaded with various electron-dense clefts (Figure 4D, micrographs 7-12). Meanwhile, healthy control mice of the same strain did not show any cleft accumulation over the entire study frame (data not shown). EM micrographs of AEC2 showed no morphological alterations.

\section{Absence of SP-C leads to impaired cholesterol metabolism in alveolar macrophages}

Due to the notable appearance of electron-dense inclusions only in the alveolar macrophages of SP-C $\mathrm{KO}$ lungs, we investigated the cholesterol metabolism in these cells. Expression of cholesterol efflux transporters, such as ATP binding cassette A1 (Abca1) and G1 (Abcg1), as well as regulatory elements of the metabolism of cholesterol, such as the gene encoding the low-density lipoprotein $(L d l r)$ receptor, the liver $\mathrm{x}$ receptor alpha (Lxra), the cholesterol-25-hydroxlyase (Ch25h) and the sterol-response element binding 
protein 2 (Srebp2) steadily increased over the first 30 weeks (Figure 5A). In addition, their expression significantly dropped from week 30 to 40 and was hardly detectable at 50 and 60 weeks. At the same time, total cholesterol amounts relative to total lung tissue exhibited a significant and constant increase (Figure 5B) with advancing age, as well as for the healthy 129Sv mice. In addition, the mixed-effect statistical analysis revealed that age was the main contributor to the changes in total cholesterol (Suppl. Table 3).

Interestingly, expression rates of cholesterol related genes were mirrored by gene expression of macrophage activator chitinase-like-3 (Ym1) (Figure 5A). In contrast, slight changes in gene expression of BAL cells from healthy animals were observed (Suppl. Figure 5A). In vitro, engulfment ability of macrophages from SP-C KO BAL was reduced when exposed to lipid, cholesterol-laden lipid and SP-Claden lipid vesicles compared to WT macrophages (Figure 5C). However, the addition of both cholesterol and SP-C to the lipid vesicles increased the uptake up to control conditions (SP-C KO macrophages exposed to lipid vesicles) and to their WT counterpart for this condition (WT macrophages exposed to cholesterol + SP-C-laden lipid vesicles). In addition, we analyzed the uptake of a mouse macrophage cell line, MHS-C in its ability to uptake lipid vesicles with/without cholesterol and/or SP-C (Figure 5D) and changes in cholesterol metabolism and transport gene expression (Figure 5E, 5F and 5G). Interestingly, the addition of SP-C to the cholesterol-laden vesicles increased not only the uptake but also further activated genes for cholesterol metabolism and transport (such as Pparg, SraI, Abca1, Abcg1, Lxrb and Srebp2).

\section{Structure-function relationship in the aging SP-C KO lung}

Peripheral arterial oxygen saturation $\left(\mathrm{SpO}_{2}\right)$ level was progressively reduced at older ages. Meanwhile, $\mathrm{SpO}_{2}$ in control mice remained unimpaired up to the age of 60 weeks (Figure 6A). In addition, the mixedeffect statistical analysis revealed that the genotype (group) was the main contributor to these changes (Suppl. Table 3). $\mu \mathrm{CT}$ imaging of a 60 -week-old male SP-C KO mice showed multiple subpleural areas of 
consolidated lung tissue (Figure 6B). Similarly, an analogous thoracic HR-CT image of a 75-year-old IPF patient exhibited subpleural reticular septal thickening adjacent to cystic airspace enlargement (Figure 6C).

Over the whole study, increasing fractions of non-ventilated parenchyma correlated with loss of alveolar surface at the light microscopic level $(\mathrm{r}=-0,455, \mathrm{p}=0,001)$ (Figure 6D). Furthermore, absolute lung volume and surface density exhibited an inverse relationship ( $\mathrm{r}=-0,445, \mathrm{p}=0,001)$ (Figure 6G). Rising inspiratory capacity correlated significantly with an increase in ductal airspace volume fraction $(\mathrm{r}=0,292$, $\mathrm{p}=0,039$ ) (Figure 6E). Increase in tissue damping was significantly proportional to rising septal thickness $(\mathrm{r}=0,290, \mathrm{p}=0,044)$ (Figure $6 \mathrm{~F})$, indicating pronounced tissue rigidity in thickened interalveolar septa. Simultaneously, a negative correlation was found between septal thickness and the fraction of ventilated parenchyma $(\mathrm{r}=-0,532, \mathrm{p}<0,001)$ (Figure 6I). A summary of correlation statistics is provided in Table 2.

\section{Discussion}

Over a 60 weeks period both adaptive and compensatory mechanisms may be activated to facilitate the main function of the lung, gas exchange, in SP-C deficient mice. These mice suffered a mild decline in lung function, with reduced $\mathrm{SpO}_{2}$ values (Figure 6A) during re-organization of air-spaces, but weeks before fibrotic wounds were detected. Similarly, it could be hypothesized that human patients with IPF may undergo re-arrangement of air-spaces years before symptoms appear and they are diagnosed. This animal model was first developed and described by Glasser and colleagues (19). They demonstrated altered stability of lung surfactant activity from SP-C $\mathrm{C}^{-/-}$mice compared to $\mathrm{SP}_{-} \mathrm{C}^{+/+}$mice, especially at low bubble volumes (in vitro) and low lung volumes (in vivo). It has already been described that SP-C is critical for the stability of the lipid surfactant film at the interface $(17,45)$, the lack of this protein may lead to collapse of small alveoli.

Interestingly, it has been reported that SP-C KO mice did not have any histological differences to their WT counterparts at the embryonal age of 18.5 and postnatal day 1 (40). However, we could observed lungs 
of 10 weeks mice showing typically thickened septal walls and shortened alveolar septal tips suggesting a delay development, which seems to be normalized at the age of 20 weeks (Figure 2A). In addition, higher expression of the collagen genes in this group also points at an ongoing delayed development of the lung (Figure 3C-D). Interestingly, those 10 weeks lungs contain also a higher number of BAL cells (mainly macrophages (Figure 4A and 4B)) pointing at an abnormal postnatal innate immune system. It may be possible that SP-C does not play an important role during prenatal development, but it does at the moment air enters the lung for the first time and during the first weeks of postnatal development. This suggests that without SP-C, a newly air-breathing lung may suffer from alveolar instability and collapse (we could detect higher volume densities of non-ventilated parenchyma in the KO mice at 10 weeks (Figure 1K)) due to lung surfactant instability. This instability during compression (expiration) of the alveolar surface may lead to abnormal mechanical and physical forces $(19,23,26)$. This may delay the normal postnatal development of the lung until the $10^{\text {th }}$ week of life, when we analyzed our animals. In addition, other animal models, showing SP-C deficiency, have reported abnormal lung development $(46,47)$. However, since a complete analysis of pre- and postnatal lung development in these mice is missing, we could only speculate about the potential role of SP-C on these processes.

Alveoli seemed to be recruited with high pressure (such as PEEP $6 \mathrm{cmH}_{2} \mathrm{O}$ ) in normal healthy animals, but somehow recruitment is impaired in older SP-C KO mice (Figure 1E). Therefore, these results suggest that chronic alveolar instability seemed to lead to permanent de-recruitability of alveoli in 50- and 60-weeks old SP-C KO mice. This permanent de-recruitment leads to changes in H (tissue elastance) and G (tissue damping) with age resulting in differences in $\eta$ at the age of 60 weeks. Differences in H and G towards progressive loss of elastance and tissue damping have also been described in the elastase-induced emphysema mouse model (48) accompanied by an increase in $\eta$. Increases in $\eta$ were also related to increased heterogeneity throughout the lung (49) in complex disease phenotypes. Therefore, the evidences from this study suggests a complex disease phenotype where over-expansion (emphysema-like phenotype) 
of air spaces and consolidated collapsed (de-recruited alveoli) regions co-exist within the lungs of SP-C KO mice. These results are supported by the lung micrographs in figure $2 \mathrm{~A}$ and suggest that over-distension of ductal and alveolar spaces precedes the consolidation of lung tissue starting at week 40 of age. In addition, septal wall thickness tended to increase in the 40 to 60-week groups (Figure 2G). These changes were not statistically significant mainly due to the increasing heterogeneity in the lungs (50). Moreover, although fibrotic alterations have been repeatedly linked to elevated lung stiffness, elastance in a pulmonary spring model only substantially increased once a certain percolation threshold was reached (51). Projected on the SP-C KO lung, these findings may explain why H showed only subtle increases at 60 weeks of age, despite the presence of multiple fibrotic lesions.

Further analysis of the septal wall composition confirmed the slight increase in collagen production at both the protein (Figure 3B) and mRNA (Figure 3C-3G) levels. As stated previously, pronounced phenotypic heterogeneity, with over distended air spaces and aberrant wound healing, masks statistically significant differences. However, this heterogeneity itself is a common feature and resembles human samples of patients suffering IPF, as shown in the HRCT scans in figure 6B and 6C.

During the 60 weeks of the study, we did not observe any sign of edema or inflammation. In addition, the total number of BAL cells in aging SP-C KO mice decreased progressively reaching the number of cells in healthy controls (Figure 4A). Analyzing the types of cells in BAL, we discovered some infiltrating cells in older lungs. At 40 weeks of age, neutrophils appeared in the BAL samples, but in a moderate proportion (less than 10\%). This proportion increased further in the 50-week group, and eosinophils appeared, but again in a moderate proportion, not enough to suspect pulmonary inflammation or lung injury (Figure 4B). Therefore, the findings of this study suggest that these infiltrating cells may contribute to the remodeling of the tissue rather than a response to inflammation or infection. This assumption is supported by previous reports where both infiltrating cell types have been related to remodeling processes in the lung $(47,52-54)$. In addition, and noteworthy, are the changes in morphology of alveolar macrophages in the aging SP-C 
$\mathrm{KO}$ mice in accordance with findings in IPF patient samples (Figure 4C). As briefly described before (40), macrophages of SP-C KO mice contain electron dense crystals in their cytoplasm (Figure 4D). Crystals were first detected in animals at 30 weeks of age. While in human patients this may be a hallmark of an eosinophilic pneumonia, in some cases associated with pulmonary fibrosis (55), the appearance of crystals before the infiltration of eosinophils, or any other infiltrating cell as well as any sign of fibrotic remodeling in the SP-C KO lungs, discards the hypothesis. On the one hand, those crystals are similar to cholesterol crystals seen in macrophages throughout the literature in the presence of cholesterol (56-59). The 129Sv strain exhibits abnormal absorption of dietary cholesterol (60) and is widely used in the study of cholesterol metabolism. Besides, this macrophage phenotype has not been described in other SP-C KO strains, with BALBc or B6N background. We observed a notable increase in cholesterol in the lung tissue of the SP-C KO mice from the 30 weeks of age (Figure 5B). However, the same pattern was also observed for their healthy controls' counterparts (Figure 5B) but crystals were not found in alveolar macrophages. In this regard, Romero and colleagues (61) showed increased amounts of cholesterol in lung tissue of mice after bleomycin treatment and attributed this to paracrine lipid cross-talk between alveolar epithelial cells and alveolar macrophages. Thus, initial observations reported here suggest that this cross-talk may be impaired in the absence of SP-C, in our model. Other lipid transporters have also been reported to be involved in development of fibrosis, including ApoE, ApoA1 and ABCG1 (62-65). Interestingly gene expression of cholesterol metabolism and transport genes showed a biphasic behavior as well as cholesterol content in the lung. When the genes under study are down-regulated, cholesterol started accumulating in the lung, right at week 30, where the first crystals appear under electron microscopy (Figure 4F, 5A and 5B). In addition, in vitro experiments supplementing cholesterol-laden lipid vesicles with SP-C enhanced not only the uptake of those vesicles by MH-S, but also resulted in an increased expression of genes related to cholesterol metabolism and transport (such as Pparg, SraI, Abca1, Abcg1, Lxrb and Srebp2). This support the 
assumption that enhanced metabolism and mobilization of cholesterol in alveolar macrophages may be regulated by SP-C in alveolar macrophages.

Cholesterol metabolism has not been deeply studied in lung fibrosis patients. Nowadays there is growing evidence that lipid metabolism is impaired in lung fibrosis $(36,37,66)$, but there is no data specific regarding to cholesterol. Interestingly, it is not very surprising that with the average age of IPF patients, around 60 years old, many of them suffer from co-morbidities such as hypercholesterolemia. Kreuter and colleages published some interesting analysis (67-69) on the potential effect of the uptake of statins during the treatment of IPF with Nintedanib. Even though there is much controversy around it, they concluded that patients under treatment of statins and Nintedanib showed a slower/delayed loss of FEV, pointing at a potential beneficial effect of the lowering down cholesterol during treatment of IPF. No pre-clinical data is found about this effect yet in the literature, so we could only speculate on the effect of cholesterol in the progression of the disease. Nevertheless, this opens a new field of research in the future and new therapeutic strategies, which should first undergo pre-clinical studies.

In conclusion, the findings of this study suggest that overall loss of SP-C results in an age-dependent complex, heterogeneous phenotype characterized by a combination of overdistended air spaces and fibrotic wounds that resembles CPFE (Combined Pulmonary Fibrosis and Emphysema) in IPF human patients. Interestingly, this remarkable phenotype is unique to the 129Sv strain, which was previously shown to have an increased absorption of cholesterol, thus linking the accumulation of cholesterol and the absence of SP-C to a fibrotic remodeling process. Besides, addition of SP-C to cholesterol-laden lipid vesicles enhanced the expression of cholesterol metabolism and transport genes in alveolar macrophages, pointing towards a new lipid-protein axis involved in lung remodeling. 
Funding: This research was funded by Biomedical Research in Endstage and Obstructive Lung Disease (BREATH), Member of the German Centre for Lung Research (DZL), Cluster of Excellence REBIRTH (Regenerative Biology to Reconstructive Therapy Hannover), and HilF program (Hochschulinterne Leistungsförderung, MHH). NR, BGA and JPG acknowledge funding from Spanish Ministry of Science and Universities (RTI2018-094564-B-I00) and the regional Government of Madrid (P2018/NMT-4389).

Acknowledgments: The authors thank the excellence technical support of Carina Vogt and Andrea Herden. N.R. also acknowledges an F.P.U (Formación Profesorado Universitario) fellowship -AP2012/5099and a short-term fellowship -EST15/00594 - granted by the Spanish Ministry of Education, Culture and Sport.

Conflicts of Interest: The authors declare no conflict of interest. 


\section{References}

1. Selman M, Thannickal VJ, Pardo A, Zisman DA, Martinez FJ, Lynch JP. Idiopathic Pulmonary Fibrosis. Drugs 2004;64:405-430.

2. Raghu G, Remy-Jardin M, Myers JL, Richeldi L, Ryerson CJ, Lederer DJ, Behr J, Cottin V, Danoff SK, Morell F, Flaherty KR, Wells A, Martinez FJ, Azuma A, Bice TJ, Bouros D, Brown KK, Collard HR, Duggal A, Galvin L, Inoue Y, Jenkins RG, Johkoh T, Kazerooni EA, Kitaichi M, Knight SL, Mansour G, Nicholson AG, Pipavath SNJ, et al. Diagnosis of Idiopathic Pulmonary Fibrosis. An Official ATS/ERS/JRS/ALAT Clinical Practice Guideline. Am J Respir Crit Care Med 2018;198:e44-e68.

3. Petroulia V, Funke M, Zumstein P, Berezowska S, Ebner L, Geiser T, Torbica N, Heverhagen J, Poellinger A. Increased Expiratory Computed Tomography Density Reveals Possible Abnormalities in Radiologically Preserved Lung Parenchyma in Idiopathic Pulmonary Fibrosis. Invest Radiol 2018;53:

4. Mai C, Verleden SE, McDonough JE, Willems S, De Wever W, Coolen J, Dubbeldam A, Van Raemdonck DE, Verbeken EK, Verleden GM, Hogg JC, Vanaudenaerde BM, Wuyts WA, Verschakelen JA. Thin-Section CT Features of Idiopathic Pulmonary Fibrosis Correlated with MicroCT and Histologic Analysis. Radiology 2016;283:252-263.

5. García-Sancho C, Buendía-Roldán I, Fernández-Plata MR, Navarro C, Pérez-Padilla R, Vargas MH, Loyd JE, Selman M. Familial pulmonary fibrosis is the strongest risk factor for idiopathic pulmonary fibrosis. Respir Med 2011;105:1902-1907. 
6. Hodgson U, Laitinen T, Tukiainen P. Nationwide prevalence of sporadic and familial idiopathic pulmonary fibrosis: evidence of founder effect among multiplex families in Finland. Thorax 2002;57:338 LP - 342.

7. Sallese A, Suzuki T, McCarthy C, Bridges J, Filuta A, Arumugam P, Shima K, Ma Y, Wessendarp M, Black D, Chalk C, Carey B, Trapnell BC. Targeting cholesterol homeostasis in lung diseases. Sci Rep $2017 ; 7: 10211$.

8. Marshall RP, Puddicombe A, Cookson WOC, Laurent GJ. Adult familial cryptogenic fibrosing alveolitis in the United Kingdom. Thorax 2000;55:143 LP - 146.

9. Allen RJ, Porte J, Braybrooke R, Flores C, Fingerlin TE, Oldham JM, Guillen-Guio B, Ma S-F, Okamoto T, John AE, Obeidat M, Yang I V, Henry A, Hubbard RB, Navaratnam V, Saini G, Thompson N, Booth HL, Hart SP, Hill MR, Hirani N, Maher TM, McAnulty RJ, Millar AB, Molyneaux PL, Parfrey H, Rassl DM, Whyte MKB, Fahy WA, et al. Genetic variants associated with susceptibility to idiopathic pulmonary fibrosis in people of European ancestry: a genome-wide association study. Lancet Respir Med 2017;5:869-880.

10. Fingerlin TE, Murphy E, Zhang W, Peljto AL, Brown KK, Steele MP, Loyd JE, Cosgrove GP, Lynch D, Groshong S, Collard HR, Wolters PJ, Bradford WZ, Kossen K, Seiwert SD, du Bois RM, Garcia CK, Devine MS, Gudmundsson G, Isaksson HJ, Kaminski N, Zhang Y, Gibson KF, Lancaster LH, Cogan JD, Mason WR, Maher TM, Molyneaux PL, Wells AU, et al. Genome-wide association study identifies multiple susceptibility loci for pulmonary fibrosis. Nat Genet, 2013/04/14. 2013;45:613- 
620.

11. Armanios M. Telomerase and idiopathic pulmonary fibrosis. Mutat Res, 2011/11/04. 2012;730:52-

58.

12. Kropski JA, Blackwell TS. Progress in Understanding and Treating Idiopathic Pulmonary Fibrosis.

Annu Rev Med 2019;70:211-224.

13. Manolio TA, Collins FS, Cox NJ, Goldstein DB, Hindorff LA, Hunter DJ, McCarthy MI, Ramos EM,

Cardon LR, Chakravarti A, Cho JH, Guttmacher AE, Kong A, Kruglyak L, Mardis E, Rotimi CN, Slatkin

M, Valle D, Whittemore AS, Boehnke M, Clark AG, Eichler EE, Gibson G, Haines JL, Mackay TFC,

McCarroll SA, Visscher PM. Finding the missing heritability of complex diseases. Nature

2009;461:747.

14. Borie $R$, Kannengiesser $C$, Nathan $N$, Tabèze L, Pradère $P$, Crestani B. Familial pulmonary fibrosis.

Rev Mal Respir 2015;32:413-434.

15. McCarthy MI, Abecasis GR, Cardon LR, Goldstein DB, Little J, Ioannidis JPA, Hirschhorn JN.

Genome-wide association studies for complex traits: consensus, uncertainty and challenges. Nat

Rev Genet 2008;9:356.

16. van Moorsel CHM, van Oosterhout MFM, Barlo NP, de Jong PA, van der Vis JJ, Ruven HJT, van Es

HW, van den Bosch JMM, Grutters JC. Surfactant Protein C Mutations Are the Basis of a Significant

Portion of Adult Familial Pulmonary Fibrosis in a Dutch Cohort. Am J Respir Crit Care Med

2010;182:1419-1425. 
17. Schürch D, Ospina OL, Cruz A, Pérez-Gil J. Combined and independent action of proteins SP-B and SP-C in the surface behavior and mechanical stability of pulmonary surfactant films. Biophys J 2010;99:3290-3299.

18. Han S, Mallampalli RK. The Role of Surfactant in Lung Disease and Host Defense against Pulmonary Infections. Ann Am Thorac Soc 2015;12:765-774.

19. Glasser SW, Burhans MS, Korfhagen TR, Na C-L, Sly PD, Ross GF, Ikegami M, Whitsett JA. Altered stability of pulmonary surfactant in SP-C-deficient mice. Proc Natl Acad Sci 2001;98:6366-6371.

20. Gómez-Gil L, Schürch D, Goormaghtigh E, Pérez-Gil J. Pulmonary Surfactant Protein SP-C Counteracts the Deleterious Effects of Cholesterol on the Activity of Surfactant Films under Physiologically Relevant Compression-Expansion Dynamics. Biophys J 2009;97:2736-2745.

21. Pérez-Gil J. Structure of pulmonary surfactant membranes and films: The role of proteins and lipidprotein interactions. Biochim Biophys Acta - Biomembr 2008;1778:1676-1695.

22. Whitsett JA, Wert SE, Weaver TE. Diseases of Pulmonary Surfactant Homeostasis. Annu Rev Pathol Mech Dis 2015;10:371-393.

23. Mulugeta S, Nureki S-I, Beers MF. Lost after translation: insights from pulmonary surfactant for understanding the role of alveolar epithelial dysfunction and cellular quality control in fibrotic lung disease. Am J Physiol Lung Cell Mol Physiol, 2015/07/17. 2015;309:L507-L525.

24. Kurland G, Deterding RR, Hagood JS, Young LR, Brody AS, Castile RG, Dell S, Fan LL, Hamvas A, 
Hilman BC, Langston C, Nogee LM, Redding GJ. An Official American Thoracic Society Clinical Practice Guideline: Classification, Evaluation, and Management of Childhood Interstitial Lung Disease in Infancy. Am J Respir Crit Care Med 2013;188:376-394.

25. Phelps DS, Floros J. Localization of Pulmonary Surfactant Proteins Using Immunohistochemistry and Tissue in Situ Hybridization. Exp Lung Res 1991;17:985-995.

26. Panda AK, Lang CJ, Daniels CB, Possmayer F, Perez-Gil J, Maina JN, Veldhuizen RA, Biswas SC, Hetz SK, Hall SB, Yan W, Bernhard W, Orgeig S. The anatomy, physics, and physiology of gas exchange surfaces: is there a universal function for pulmonary surfactant in animal respiratory structures? Integr Comp Biol 2007;47:610-627.

27. Kipen HM, Lilis R, Suzuki Y, Valciukas JA, Selikoff IJ. Pulmonary fibrosis in asbestos insulation workers with lung cancer: a radiological and histopathological evaluation. Br J Ind Med 1987;44:96100.

28. Yoshida T, Tuder RM. Pathobiology of Cigarette Smoke-Induced Chronic Obstructive Pulmonary Disease. Physiol Rev 2007;87:1047-1082.

29. Cohen RAC, Patel A, Green FHY. Lung Disease Caused by Exposure to Coal Mine and Silica Dust. Semin Respir Crit Care Med 2008;29:651-661.

30. Knudsen $\mathrm{L}$, Ochs $\mathrm{M}$. The micromechanics of lung alveoli: structure and function of surfactant and tissue components. Histochem Cell Biol 2018;150:661-676. 
31. Mead J, Takishima T, Leith D. Stress distribution in lungs: a model of pulmonary elasticity. J Appl Physiol 1970;28:596-608.

32. Lopez-Rodriguez E, Boden C, Echaide M, Perez-Gil J, Kolb M, Gauldie J, Maus UA, Ochs M, Knudsen L. Surfactant dysfunction during overexpression of TGF- $\beta 1$ precedes profibrotic lung remodeling in vivo. Am J Physiol Cell Mol Physiol 2016;310:L1260-L1271.

33. Chilosi M, Carloni A, Rossi A, Poletti V. Premature lung aging and cellular senescence in the pathogenesis of idiopathic pulmonary fibrosis and COPD/emphysema. Transl Res 2013;162:156173.

34. Brandenberger C, Mühlfeld C. Mechanisms of lung aging. Cell Tissue Res 2017;367:469-480.

35. Janssens JP, Pache JC, Nicod LP. Physiological changes in respiratory function associated with ageing. Eur Respir J 1999;13:197 LP - 205.

36. Romero F, Hong X, Shah D, Kallen CB, Rosas I, Guo Z, Schriner DL, Barta J, Shaghaghi H, Hoek JB, Mesaros C, Choi AM, Snyder NW, Summer R. Lipid synthesis is required to resolve endoplasmic reticulum stress and limit fibrotic responses in the lung. Am J Respir Cell Mol Biol 2018;59:225-236.

37. Romero F, Shah D, Duong M, Penn RB, Fessler MB, Madenspacher J, Stafstrom W, Kavuru M, Lu B, Kallen CB, Walsh K, Summer R. A Pneumocyte - Macrophage Paracrine Lipid Axis Drives the Lung toward Fibrosis. Am J Respir Cell Mol Biol 2015;53:74-86.

38. Lopez-Rodriguez E, Gay-Jordi G, Mucci A, Lachmann N, Serrano-Mollar A. Lung surfactant 
metabolism: early in life, early in disease and target in cell therapy. Cell Tissue Res 2017;367:721735.

39. Chu SG, Villalba JA, Liang X, Xiong K, Tsoyi K, Ith B, Ayaub EA, Tatituri R V, Byers DE, Hsu F-F, ElChemaly S, Kim EY, Shi Y, Rosas IO. Palmitic Acid-Rich High Fat Diet Exacerbates Experimental Pulmonary Fibrosis by Modulating Endoplasmic Reticulum Stress. Am J Respir Cell Mol Biol 2019;doi:10.1165/rcmb.2018-0324OC.

40. Glasser SW, Detmer EA, Ikegami M, Na C-L, Stahlman MT, Whitsett JA. Pneumonitis and Emphysema in sp-C Gene Targeted Mice. J Biol Chem 2003;278:14291-14298.

41. Beike L, Wrede C, Hegermann J, Lopez-Rodriguez E, Kloth C, Gauldie J, Kolb M, Maus UA, Ochs M, Knudsen L. Surfactant dysfunction and alveolar collapse are linked with fibrotic septal wall remodeling in the TGF- $\beta 1$-induced mouse model of pulmonary fibrosis. Lab Investig 2019;at <https://doi.org/10.1038/s41374-019-0189-x>.

42. Ochs M, Mühlfeld C. Quantitative microscopy of the lung: a problem-based approach. Part 1: basic principles of lung stereology. Am J Physiol Cell Mol Physiol 2013;305:L15-L22.

43. Mühlfeld C, Ochs M. Quantitative microscopy of the lung: a problem-based approach. Part 2: stereological parameters and study designs in various diseases of the respiratory tract. Am J Physiol Cell Mol Physiol 2013;305:L205-L221.

44. Kesava Reddy G, Enwemeka CS. A simplified method for the analysis of hydroxyproline in biological tissues. Clin Biochem 1996;29:225-229. 
45. Roldan N, Pérez-Gil J, Morrow MR, García-Álvarez B. Divide \& Conquer: Surfactant Protein SP-C and Cholesterol Modulate Phase Segregation in Lung Surfactant. Biophys J 2017;113:847-859.

46. Bridges JP, Wert SE, Nogee LM, Weaver TE. Expression of a Human Surfactant Protein C Mutation Associated with Interstitial Lung Disease Disrupts Lung Development in Transgenic Mice. J Biol Chem 2003;278:52739-52746.

47. Nureki S-I, Tomer Y, Venosa A, Katzen J, Russo SJ, Jamil S, Barrett M, Nguyen V, Kopp M, Mulugeta S, Beers MF. Expression of mutant Sftpc in murine alveolar epithelia drives spontaneous lung fibrosis. J Clin Invest, 2018/08/13. 2018;128:4008-4024.

48. Ito S, Ingenito EP, Brewer KK, Black LD, Parameswaran H, Lutchen KR, Suki B. Mechanics, nonlinearity, and failure strength of lung tissue in a mouse model of emphysema: possible role of collagen remodeling. J Appl Physiol 2005;98:503-511.

49. Poynter ME, Bates JHT, Lundblad LK a., Leclair T, Irvin CG, Thompson-Figueroa J, Sullivan MJ. Tumor Necrosis Factor- $\alpha$ Overexpression in Lung Disease. Am J Respir Crit Care Med 2005;171:1363-1370.

50. Bates JHT, Davis GS, Majumdar A, Butnor KJ, Suki B. Linking parenchymal disease progression to changes in lung mechanical function by percolation. Am J Respir Crit Care Med 2007;176:617-623.

51. Suki B, Bates JHT. Lung tissue mechanics as an emergent phenomenon. J Appl Physiol 2011;110:1111-8. 
52. Gregory AD, Kliment CR, Metz HE, Kim K-H, Kargl J, Agostini BA, Crum LT, Oczypok EA, Oury TA, Houghton AM. Neutrophil elastase promotes myofibroblast differentiation in lung fibrosis. J Leukoc Biol 2015;98:143-152.

53. Gieseck III RL, Wilson MS, Wynn TA. Type 2 immunity in tissue repair and fibrosis. Nat Rev Immunol 2017;18:62.

54. Katzen J, Wagner BD, Venosa A, Kopp M, Tomer Y, Russo SJ, Headen AC, Basil MC, Stark JM, Mulugeta S, Deterding RR, Beers MF. An SFTPC BRICHOS mutant links epithelial ER stress and spontaneous lung fibrosis. JCI Insight 2019;4:.

55. Allen JN, Davis WB. Eosinophilic lung diseases. Am J Respir Crit Care Med 1994;150:1423-1438.

56. Gilmore LB, Talley FA, Hook GE. Classification and morphometric quantitation of insoluble materials from the lungs of patients with alveolar proteinosis. Am J Pathol 1988;133:252-64.

57. Klinkner AM, Waites CR, Kerns WD, Bugelski PJ. Evidence of foam cell and cholesterol crystal formation in macrophages incubated with oxidized LDL by fluorescence and electron microscopy. $J$ Histochem Cytochem 1995;43:1071-1078.

58. Tangirala RK, Jerome WG, Jones NL, Small DM, Johnson WJ, Glick JM, Mahlberg FH, Rothblat GH. Formation of cholesterol monohydrate crystals in macrophage-derived foam cells. J Lipid Res 1994;35:93-104.

59. de Aguiar Vallim TQ, Lee E, Merriott DJ, Goulbourne CN, Cheng J, Cheng A, Gonen A, Allen RM, 
Palladino END, Ford DA, Wang T, Baldán Á, Tarling EJ. ABCG1 regulates pulmonary surfactant metabolism in mice and men. J Lipid Res 2017;58:941-954.

60. Jolley CD, Dietschy JM, Turley SD. Genetic differences in cholesterol absorption in $129 / \mathrm{Sv}$ and C57BL/6 mice: effect on cholesterol responsiveness. Am J Physiol Liver Physiol 1999;276:G1117G1124.

61. Romero F, Shah D, Duong M, Penn RB, Fessler MB, Madenspacher J, Stafstrom W, Kavuru M, Lu B, Kallen CB, Walsh K, Summer R. A Pneumocyte-Macrophage Paracrine Lipid Axis Drives the Lung toward Fibrosis. Am J Respir Cell Mol Biol 2014;53:74-86.

62. Gowdy KM, Fessler MB. Emerging roles for cholesterol and lipoproteins in lung disease. Pulm Pharmacol Ther 2013;26:430-437.

63. Samokhin AO, Bühling F, Theissig F, Brömme D. ApoE-Deficient Mice on Cholate-Containing HighFat Diet Reveal a Pathology Similar to Lung Sarcoidosis. Am J Pathol 2010;176:1148-1156.

64. Kim TH, Lee YH, Kim KH, Lee SH, Cha JY, Shin EK, Jung S, Jang AS, Park SW, Uh ST, Kim YH, Park JS, Sin HG, Youm W, Koh ES, Cho SY, Paik YK, Rhim TY, Park CS. Role of Lung Apolipoprotein A-I in Idiopathic Pulmonary Fibrosis. Am J Respir Crit Care Med 2010;182:633-642.

65. Yao X, Gordon EM, Figueroa DM, Barochia A V, Levine SJ. Emerging Roles of Apolipoprotein E and Apolipoprotein A-I in the Pathogenesis and Treatment of Lung Disease. Am J Respir Cell Mol Biol 2016;55:159-169. 
66. Fessler MB. A New Frontier in Immunometabolism. Cholesterol in Lung Health and Disease. Ann Am Thorac Soc 2017;14:S399-S405.

67. Kreuter M, Bonella F, Maher TM, Costabel U, Spagnolo P, Weycker D, Kirchgaessler KU, Kolb M. Effect of statins on disease-related outcomes in patients with idiopathic pulmonary fibrosis. Thorax 2017;72:148-153.

68. Kreuter M, Ehlers-Tenenbaum S, Palmowski K, Bruhwyler J, Oltmanns U, Muley T, Heussel CP, Warth A, Kolb M, Herth FJF. Impact of comorbidities on mortality in patients with idiopathic pulmonary fibrosis. PLoS One 2016;11:1-18.

69. Kreuter M, Costabel U, Richeldi L, Cottin V, Wijsenbeek M, Bonella F, Bendstrup E, Maher TM, Wachtlin D, Stowasser S, Kolb M. Statin Therapy and Outcomes in Trials of Nintedanib in Idiopathic Pulmonary Fibrosis. Respiration 2018;95:317-326. 


\section{Figure legends}

Figure 1. Impaired alveolar recruitment is accompanied by increased tissue stiffness in the lungs of SPC KO and healthy 129Sv mice. A) Body weight (BW); B) Lung volume (ml); C) Inspiratory capacity (IC); and D) Static Compliance (Cst) over time. E) Tissue elastance $(\mathrm{H})$ as indicator of distal lung tissue stiffness was obtained during forced oscillation technique and calculated according to the constant phase model at PEEP $1 \mathrm{cmH}_{2} \mathrm{O}$ (black bars), $3 \mathrm{cmH}_{2} \mathrm{O}$ (grey bars) and $6 \mathrm{cmH}_{2} \mathrm{O}$ (white bars) for each age group, respectively, $\mathrm{n} \geq 8$ (black horizontal lines indicate statistically significant differences between the groups they connect p <0.05). F) tissue damping (G); and G) tissue hysteresivity $(\eta)$ were assessed at 10-60 weeks of age. H) Volume fraction $(\mathrm{Vv})$ of ventilated parenchyma (light grey) and non-ventilated parenchyma (white) within lung parenchyma of SP-C KO mice at different ages. Mean \pm SD, $n \geq 6$; horizontal black lines with an asterisk $\left.{ }^{*}\right)$ represents a statistical difference $\mathrm{p}<0.05$ between SP-C KO vs Healthy within age groups. Statistical differences over age are represented in blue for the SP-C KO group and in grey for the healthy controls. + p $<0.05$ vs. 10 weeks; \#p<0.05 vs. 20 weeks; $\$ p<0.05$ vs. 30 weeks; $<\mathrm{p}<0.05$ vs. 40 weeks.

Figure 2. Ductal airspace over distension precedes septal thickening in the SP-C KO and healthy 129Sv lung. A) Representative Toluidine-blue stained micrographs of vascular perfused-fixed murine SP-C KO lungs (inflated with air at airway pressure $=5 \mathrm{cmH}_{2} \mathrm{O}$ ), revealed thickened interalveolar septa as marker of microatelectasis (pink arrow) (A1-2). This was followed by alveo-ductal over distension (green arrow), which coincidences with alveolar size reduction in the same topographic region at an age of 20 weeks (A34). This process was found to further develop until week 30 (A5-6), predominating in the subpleural regions (A3, A5). At 40 weeks of age enlarged alveolar ducts localized next to prominent septal walls (arrowhead) (A7, A8). 10 weeks later first fibrotic lesions (yellow arrow) appeared causing tensile stress of the surrounding lung parenchyma (A9-10). After 60 weeks, septal wall thickening progressed, while alveolar destabilization in sense of collapse induration continued (A11-12). Age-dependent lung structure analysis 
of: B) alveolar airspaces density ( $\operatorname{Vv}(\mathrm{alv} / \mathrm{par}))$; C) ductal airspaces density ( $\mathrm{Vv}(\mathrm{duct} / \mathrm{par})$; D) mean linear intercept length; E) Mean volume weighted mean volume $\left(\bar{v}_{\mathrm{v}}(\mathrm{alv})\right)$; F) absolute surface of the alveolar epithelium (S(alvepi)); and G) Septal wall thickness $(\mu \mathrm{m})$ were quantified within the ventilated parenchyma (V(vent-par, lung) over age. Mean $\pm S D, n \geq 6$; horizontal black lines with an asterisk $\left(^{*}\right)$ represents a statistical difference $\mathrm{p}<0.05$ between SP-C KO vs Healthy within age groups. Statistical differences over age are represented in blue for the SP-C KO group and in grey for the healthy controls. $+\mathrm{p}<0.05$ vs. 10 weeks; \#p $<0.05$ vs. 20 weeks; $§ \mathrm{p}<0.05$ vs. 30 weeks; $<\mathrm{p}<0.05$ vs. 40 weeks.

Figure 3. SP-C KO mice exhibit altered tissue composition and aberrant connective-tissue protein gene expression. A) Masson-Goldner trichrome staining over age, showed the abundance of dense, nonventilated parenchyma areas at 10 and 50 weeks of age. At 50 weeks these lesions (arrow) were interspersed with collagen (green), while no collagen deposition was visible lungs from 10-week-old mice (arrowhead). B) Hydroxyproline level was quantified in representative tissue sections at 40, 50 and 60 weeks (*p<0.05, $\mathrm{n}=5$ ) and; C-G) RT-PCR gene expression analysis of collagen 1a1, collagen 1a2, collagen 3a1, elastin and fibronectin in healthy and SP-C KO lungs at the ages of 10-60 weeks showed decreasing expression levels becoming significant for Fn, Col1a1 and Col3a1. Normalized by Gapdh; +p<0.05 vs. 10 weeks, n=5.

Figure 4. SP-C deficiency alters the innate immune system of the lung. A) Total BALF cell count assessed in SP-C KO and healthy 129Sv mice. B) Relative quantification of leukocyte subpopulations in BALF cells of SP-C KO mice. C) Electron-microscopic micrograph of an IPF lung demonstrates the presence of intraparenchymal macrophages being loaded with electron-dense crystals (pink arrow). D) Representative electron-microscopic imaging of SP-C KO lungs over age demonstrates unaltered AEC2 morphology with physiologically shaped lamellar bodies (green arrow) (F1-6) and electron-dense intracellular inclusions with cleft formation in lung macrophages (pink arrow) (F7-12). Onset of crystal formation starts at 30 weeks of age. Detailed structural morphology of the lamellar-body-like inclusions and electron-dense clefts is provided on high-magnification micrographs (F13-18). Mean $\pm S D, n \geq 6$; horizontal black lines with an 
asterisk $\left(^{*}\right)$ represents a statistical difference $\mathrm{p}<0.05$ between SP-C KO vs Healthy within age groups. Statistical differences over age are represented in blue for the SP-C KO group and in grey for the healthy controls. $+\mathrm{p}<0.05$ vs. 10 weeks.

Figure 5. Absence of SP-C leads to impaired cholesterol metabolism in alveolar macrophages. A) RTPCR gene expression analysis of ATP binding cassette A1 (Abca1), ATP binding cassette G1 (Abcg1), cholesterol-25-hydroxylase $(C h 25 h)$, LDL receptor $(L d l r)$, liver $\mathrm{X}$ receptor alpha $(\mathrm{Lxra})$, sterol response element binding protein 2 (Srebp2) and chitinase like 3 or Ym1 (Chil3) in BALF cells. Normalized by Gapdh. B) Total Cholesterol quantification in SP-C KO and healthy 129Sv lungs per $\mu \mathrm{g}$ lung tissue at week 10-60. C) Fluorescent-lipid uptake by alveolar macrophages as percentage of engulfment, measure by FACS detection of fluorescent BAL cells from WT or SP-C KO mice. Macrophages were exposed to $0.25 \mu \mathrm{g}$ of labeled phospholipid per $10^{5}$ cells, with/without cholesterol and/or SP-C. Black horizontal lines represents $\mathrm{p}<0.05$ between WT vs KO using a t-test, light blue horizontal lines represents $\mathrm{p}<0.05$ when comparing different vesicle composition within the SP-C KO group using an ANOVA. D) MH-S cells, alveolar macrophage-like mouse cell line, were exposed to lipid vesicles laden with fluorescent cholesterol and/or SP-C and lipid uptake was measure in FACS as explained before. E) In another set of experiments macrophages exposed to vesicles with different composition during $1 \mathrm{~h}$ were collected for RNA isolation and RT-PCR analysis of expression of genes related to cholesterol metabolism and transport. F) Representative heat map of relative expression of the different genes using clustering by targets (right) and samples ordered by type (top). The green rectangle shows different targets up-regulated in the samples containing cholesterol and SP-C in comparison to samples containing only cholesterol or SP-C. G) Relative gene expression $(\Delta \Delta \mathrm{Cq}$, normalized by $A c t b)$ in the different samples ( $\mathrm{n}=6$ per group) of the most interesting upregulated genes from the heat map, Pparg, SraI, Abca1, Lxrb, Abcg1, and Srebp2). Mean \pm SD, n $\geq 6$; horizontal black lines with an asterisk $\left(^{*}\right)$ represents a statistical difference $\mathrm{p}<0.05$ between SP-C KO vs Healthy within age groups. Statistical differences over age are represented in blue for the SP-C KO group 
and in grey for the healthy controls. $+\mathrm{p}<0.05$ vs. 10 weeks; $\# \mathrm{p}<0.05$ vs. 20 weeks; $\$ p<0.05$ vs. 30 weeks; $<\mathrm{p}<0.05$ vs. 40 weeks; $>\mathrm{p}<0.05$ vs. 50 weeks.

Figure 6. Structure-function relationship in the SP-C KO lung. A) Peripheral arterial oxygen saturation $\left(\mathrm{SpO}_{2}\right)$ was measured at PEEP $3 \mathrm{cmH}_{2} \mathrm{O}$ before subsequent ventilation protocol was started in SP-C KO and healthy 129Sv mice; B) $\mu \mathrm{CT}$ imaging of a fixed SP-C KO lung shows distinct parenchymal lesions predominating in the subpleural compartments (pink arrow); C) HR-CT imaging of a 75-year-old IPF patient. The pathology impresses with reticular septal thickening, honeycomb-cysts, traction bronchiectasis, and tissue consolidation (pink arrow) in the means of UIP pattern. The pathology predominates in the subpleural regions and localizes in the direct neighborhood of over distended lung parenchyma. Statistically significant correlation of structural and mechanical parameters over the whole study period $(\bullet 10$ weeks, $₫ 20$ weeks, $\Delta 30$ weeks, $\nabla 40$ weeks, $\diamond 50$ weeks, $\circ 60$ weeks). D) Negative correlations between alveolar surface and non-ventilated parenchyma volume fraction by stereological analysis, and E) surface density and absolute lung volume. F) Proportional relationship of ductal volume fraction and inspiratory capacity acquired by FlexiVent. G) Positive correlation of mean linear intercept and absolute lung volume as independently determined structural parameters. H) Tissue damping and septal thickness exhibit a positive structure-function relationship whereas I) ventilated parenchyma volume fraction and septal thickness correlate inversely. Mean $\pm S D, n \geq 6$; horizontal black lines with an asterisk $\left(^{*}\right)$ represents a statistical difference $\mathrm{p}<0.05$ between SP-C KO vs Healthy within age groups. 


\section{Tables}

Table 1 Absolute volumes of lung compartments determined by design-based stereology in SP-C KO mice lungs. Absolute stereological lung volumes (mL) are given with mean and standard deviation (SD) for every age group. $\mathrm{V}$ (par, lung)=absolute lung parenchyma volume; $\mathrm{V}$ (non-par, lung)=absolute non-parenchyma volume; V(vent-par, lung)=absolute ventilated parenchyma volume; $\mathrm{V}$ (non-vent-par, lung)=absolute nonventilated parenchyma volume; $\mathrm{V}(\mathrm{alv}$, lung)=absolute alveolar space volume; $\mathrm{V}$ (duct, lung)=Absolute ductal airspace volume; V(sept, lung)=absolute septal volume.

\begin{tabular}{|c|c|c|c|c|c|c|c|c|c|c|c|c|}
\hline & \multicolumn{2}{|c|}{10 weeks } & \multicolumn{2}{|c|}{20 weeks } & \multicolumn{2}{|c|}{30 weeks } & \multicolumn{2}{|c|}{40 weeks } & \multicolumn{2}{c|}{50 weeks } & \multicolumn{2}{c|}{60 weeks } \\
\hline Parameter [ml] & Mean & SD & Mean & SD & Mean & SD & Mean & SD & Mean & SD & Mean & SD \\
\hline V(par/lung) & 0.34 & 0.07 & 0.35 & 0.05 & 0.63 & 0.11 & 0.42 & 0.07 & 0.53 & 0.10 & 0.49 & 0.10 \\
\hline V(non-par/lung) & 0.05 & 0.02 & 0.06 & 0.02 & 0.09 & 0.02 & 0.05 & 0.01 & 0.07 & 0.02 & 0.08 & 0.03 \\
\hline $\begin{array}{c}\text { V(vent- } \\
\text { par/lung) }\end{array}$ & 0.33 & 0.07 & 0.34 & 0.04 & 0.62 & 0.10 & 0.42 & 0.07 & 0.51 & 0.10 & 0.48 & 0.10 \\
\hline $\begin{array}{c}\text { V(non-vent- } \\
\text { par/lung) }\end{array}$ & 0.008 & 0.006 & 0.009 & 0.004 & 0.010 & 0.006 & 0.006 & 0.003 & 0.013 & 0.006 & 0.010 & 0.006 \\
\hline V(alv/lung) & 0.16 & 0.04 & 0.15 & 0.02 & 0.29 & 0.05 & 0.19 & 0.03 & 0.21 & 0.03 & 0.22 & 0.06 \\
\hline V(duct/lung) & 0.13 & 0.05 & 0.15 & 0.03 & 0.27 & 0.05 & 0.20 & 0.04 & 0.26 & 0.07 & 0.22 & 0.04 \\
\hline V(sept/lung) & 0.04 & 0.01 & 0.04 & 0.05 & 0.07 & 0.11 & 0.04 & 0.01 & 0.05 & 0.01 & 0.06 & 0.01 \\
\hline
\end{tabular}

Table 2 Statistically significant correlations following Spearman test and linear regression comprising all SP-C KO age cohorts.

\begin{tabular}{|c|c|c|c|c|}
\hline Correlating parameters & Spearman - r & $\begin{array}{c}\text { Spearman - } \\
\text { Sig. two-sided }\end{array}$ & $\mathrm{N}$ & Linear regression \\
\hline Vv(non-vent-par/par), S(alvepi,lung) & $-0.455^{* *}$ & 0.001 & 51 & $\mathrm{Y}=-1974^{*} \mathrm{X}+260.7$ \\
\hline Lung volume, Sv & $-0.445^{* *}$ & 0.001 & 51 & $\mathrm{Y}=-0.02113^{*} \mathrm{X}+0.06102$ \\
\hline IC, Vv(duct/par) & $0.292^{*}$ & 0.039 & 50 & $\mathrm{Y}=0.1339^{*} \mathrm{X}+0.3125$ \\
\hline Lung volume, Mean linear intercept & $0.495^{* *}$ & 0.000 & 51 & $\mathrm{Y}=37.91^{*} \mathrm{X}+52.61$ \\
\hline Septal thickness, G & $0.290^{*}$ & 0.044 & 49 & $\mathrm{Y}=0.2579^{*} \mathrm{X}+2.990$ \\
\hline Septal thickness, Vv(vent-par,par) & $-0.532^{* *}$ & 0.000 & 51 & $\mathrm{Y}=-0.02671^{*} \mathrm{X}+0.5584$ \\
\hline
\end{tabular}



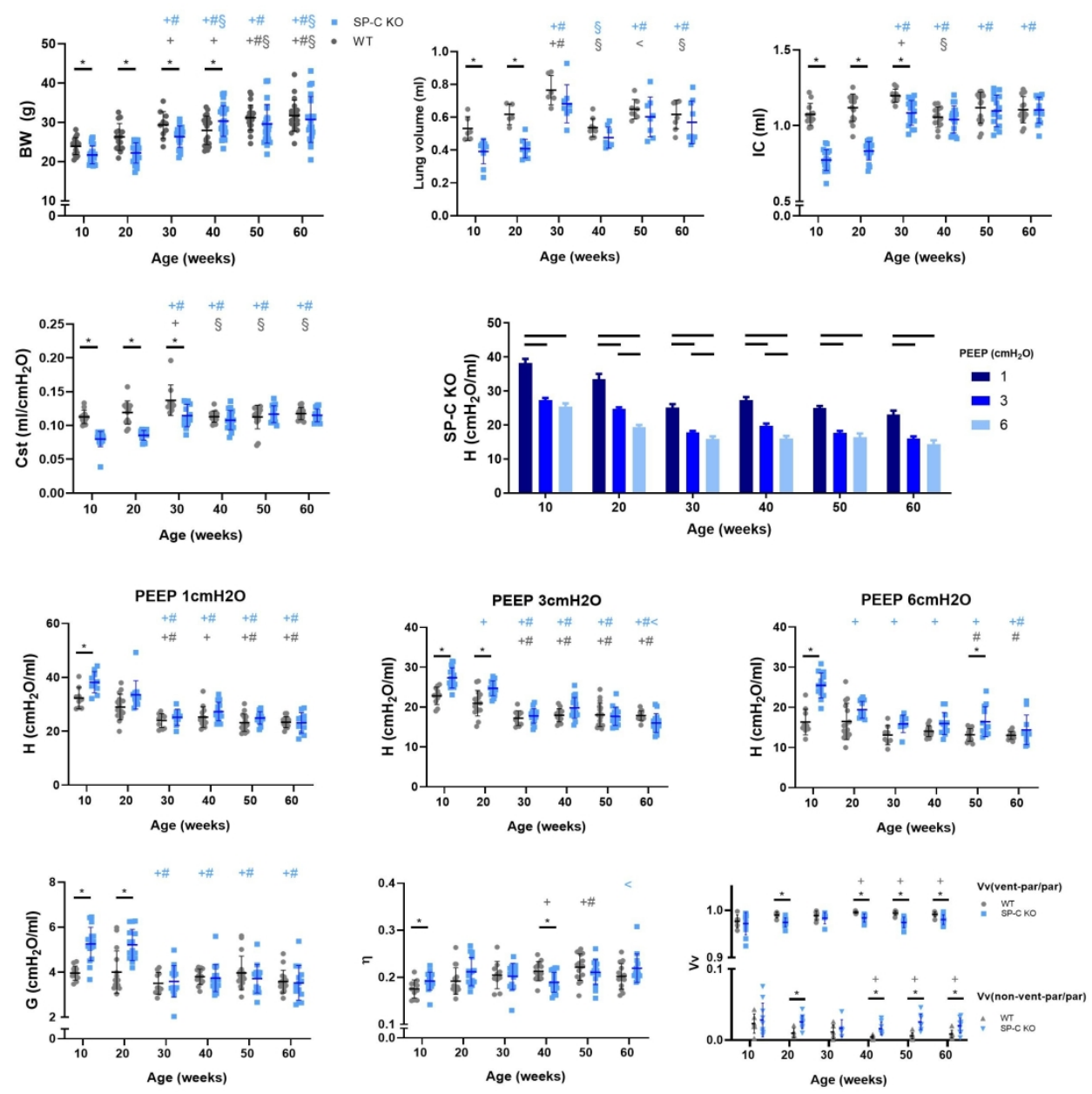

Figure 1. Impaired alveolar recruitment is accompanied by increased tissue stiffness in the lungs of SP-C KO and healthy $129 \mathrm{~Sv}$ mice. A) Body weight (BW); B) Lung volume (ml); C) Inspiratory capacity (IC); and D) Static Compliance (Cst) over time. E) Tissue elastance $(\mathrm{H})$ as indicator of distal lung tissue stiffness was obtained during forced oscillation technique and calculated according to the constant phase model at PEEP $1 \mathrm{cmH} 2 \mathrm{O}$ (black bars), $3 \mathrm{cmH} 2 \mathrm{O}$ (grey bars) and $6 \mathrm{cmH} 2 \mathrm{O}$ (white bars) for each age group, respectively, $\mathrm{n} \geq 8$ (black horizontal lines indicate statistically significant differences between the groups they connect $p<0.05$ ).

F) tissue damping (G); and G) tissue hysteresivity ( $\diamond$ ) were assessed at 10-60 weeks of age. H) Volume fraction $(\mathrm{Vv})$ of ventilated parenchyma (light grey) and non-ventilated parenchyma (white) within lung parenchyma of SP-C KO mice at different ages. Mean \pm SD, $n \geq 6$; horizontal black lines with an asterisk $(*)$ represents a statistical difference $p<0.05$ between SP-C KO vs Healthy within age groups. Statistical differences over age are represented in blue for the SP-C KO group and in grey for the healthy controls. $+p<0.05$ vs. 10 weeks; $\# p<0.05$ vs. 20 weeks; $\S p<0.05$ vs. 30 weeks; $<p<0.05$ vs. 40 weeks. 


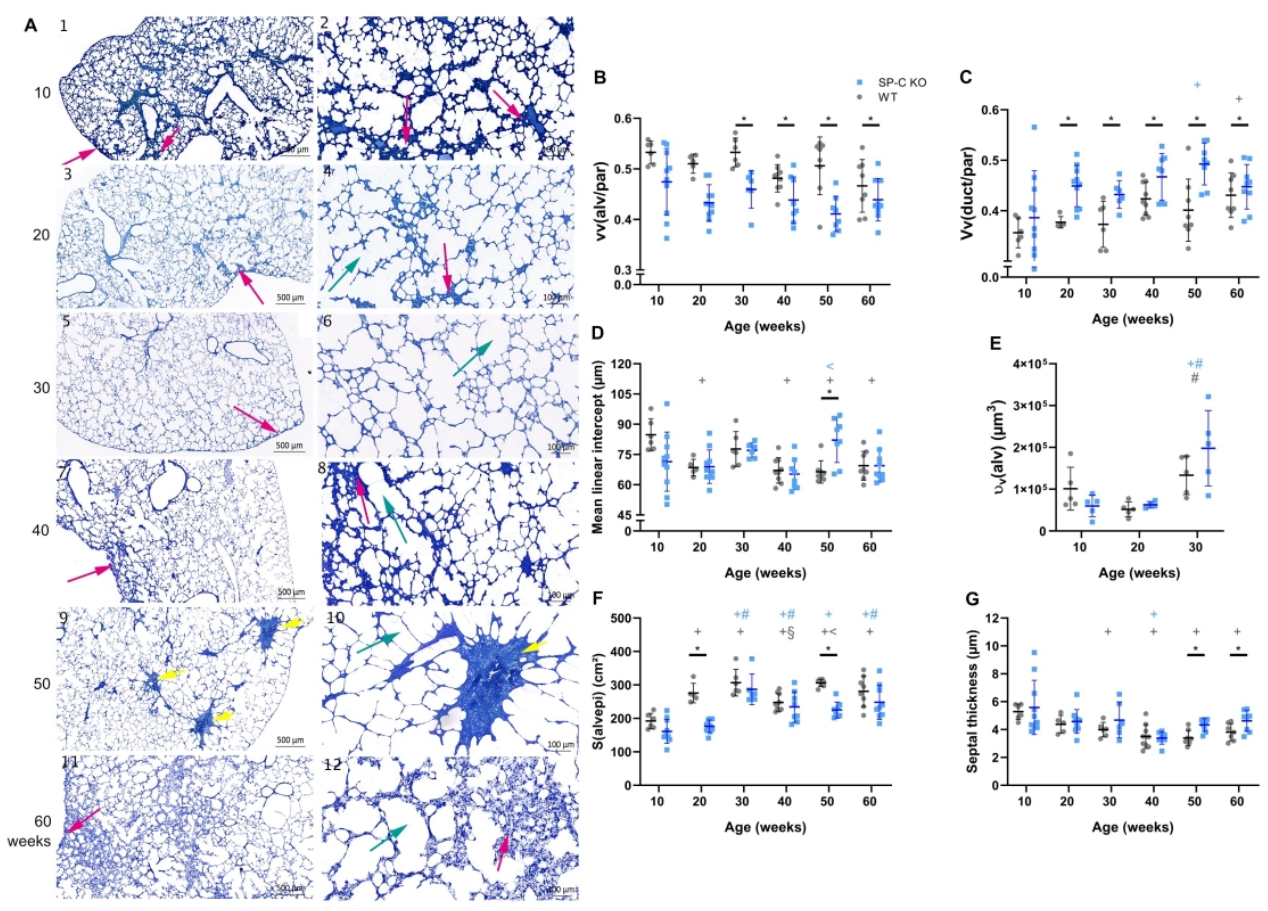

Figure 2. Ductal airspace over distension precedes septal thickening in the SP-C KO and healthy $129 \mathrm{~Sv}$ lung.

A) Representative Toluidine-blue stained micrographs of vascular perfused-fixed murine SP-C KO lungs (inflated with air at airway pressure $=5 \mathrm{cmH} 20$ ), revealed thickened interalveolar septa as marker of microatelectasis (pink arrow) (A1-2). This was followed by alveo-ductal over distension (green arrow), which coincidences with alveolar size reduction in the same topographic region at an age of 20 weeks (A3-4). This process was found to further develop until week 30 (A5-6), predominating in the subpleural regions (A3, A5). At 40 weeks of age enlarged alveolar ducts localized next to prominent septal walls (arrowhead) (A7, A8). 10 weeks later first fibrotic lesions (yellow arrow) appeared causing tensile stress of the surrounding lung parenchyma (A9-10). After 60 weeks, septal wall thickening progressed, while alveolar destabilization in sense of collapse induration continued (A11-12). Age-dependent lung structure analysis of: B) alveolar airspaces density (Vv(alv/par)); C) ductal airspaces density (Vv(duct/par); D) mean linear intercept length; E) Mean volume weighted mean volume (ūv(alv)); F) absolute surface of the alveolar epithelium (S(alvepi)); and $G$ ) Septal wall thickness $(\mu \mathrm{m})$ were quantified within the ventilated parenchyma (V(vent-par, lung) over age. Mean $\pm S D, n \geq 6$; horizontal black lines with an asterisk $\left(^{*}\right)$ represents a statistical difference $p<0.05$ between SP-C KO vs Healthy within age groups. Statistical differences over age are represented in blue for the SP-C KO group and in grey for the healthy controls. $+p<0.05$ vs. 10 weeks; \#p<0.05 vs. 20 weeks; $\S p<0.05$ vs. 30 weeks; $<p<0.05$ vs. 40 weeks.

$297 \times 209 \mathrm{~mm}(300 \times 300$ DPI $)$ 


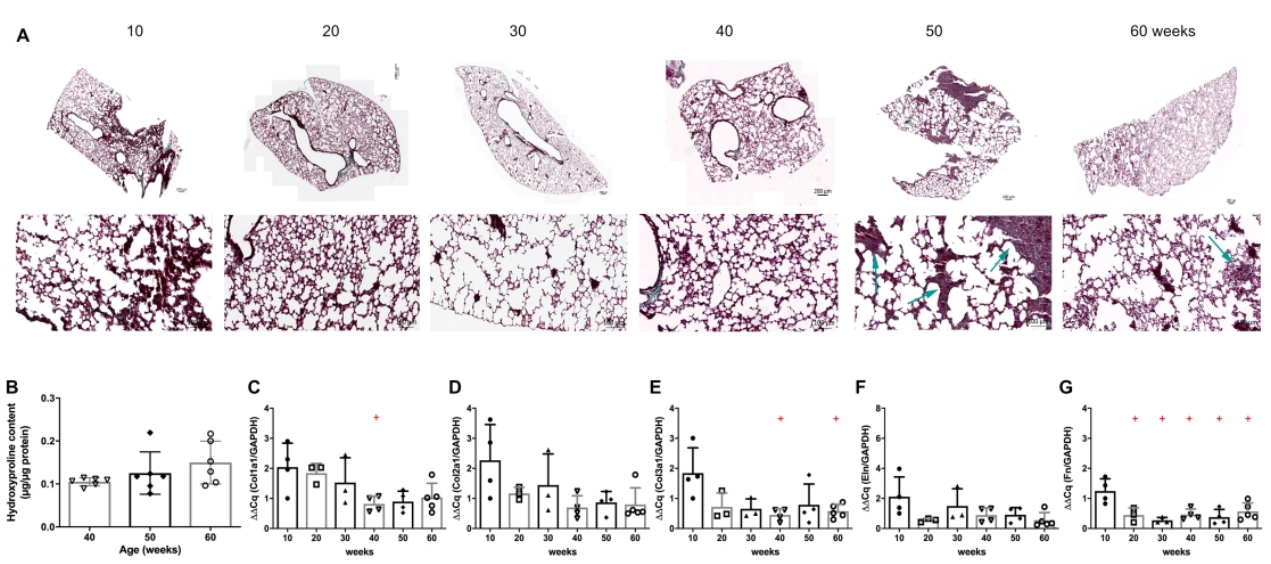

Figure 3. SP-C KO mice exhibit altered tissue composition and aberrant connective-tissue protein gene expression. A) Masson-Goldner trichrome staining over age, showed the abundance of dense, non-ventilated parenchyma areas at 10 and 50 weeks of age. At 50 weeks these lesions (arrow) were interspersed with collagen (green), while no collagen deposition was visible lungs from 10-week-old mice (arrowhead). B) Hydroxyproline level was quantified in representative tissue sections at 40,50 and 60 weeks $\left({ }^{*} p<0.05\right.$, $\mathrm{n}=5$ ) and; C-G) RT-PCR gene expression analysis of collagen 1a1, collagen 1a2, collagen 3a1, elastin and fibronectin in healthy and SP-C KO lungs at the ages of 10-60 weeks showed decreasing expression levels becoming significant for Fn, Col1a1 and Col3a1. Normalized by Gapdh; $+p<0.05$ vs. 10 weeks, $n=5$.

$297 \times 160 \mathrm{~mm}(300 \times 300$ DPI $)$ 
A

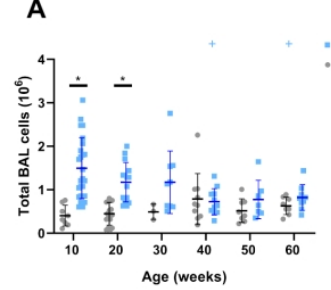

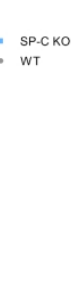

B
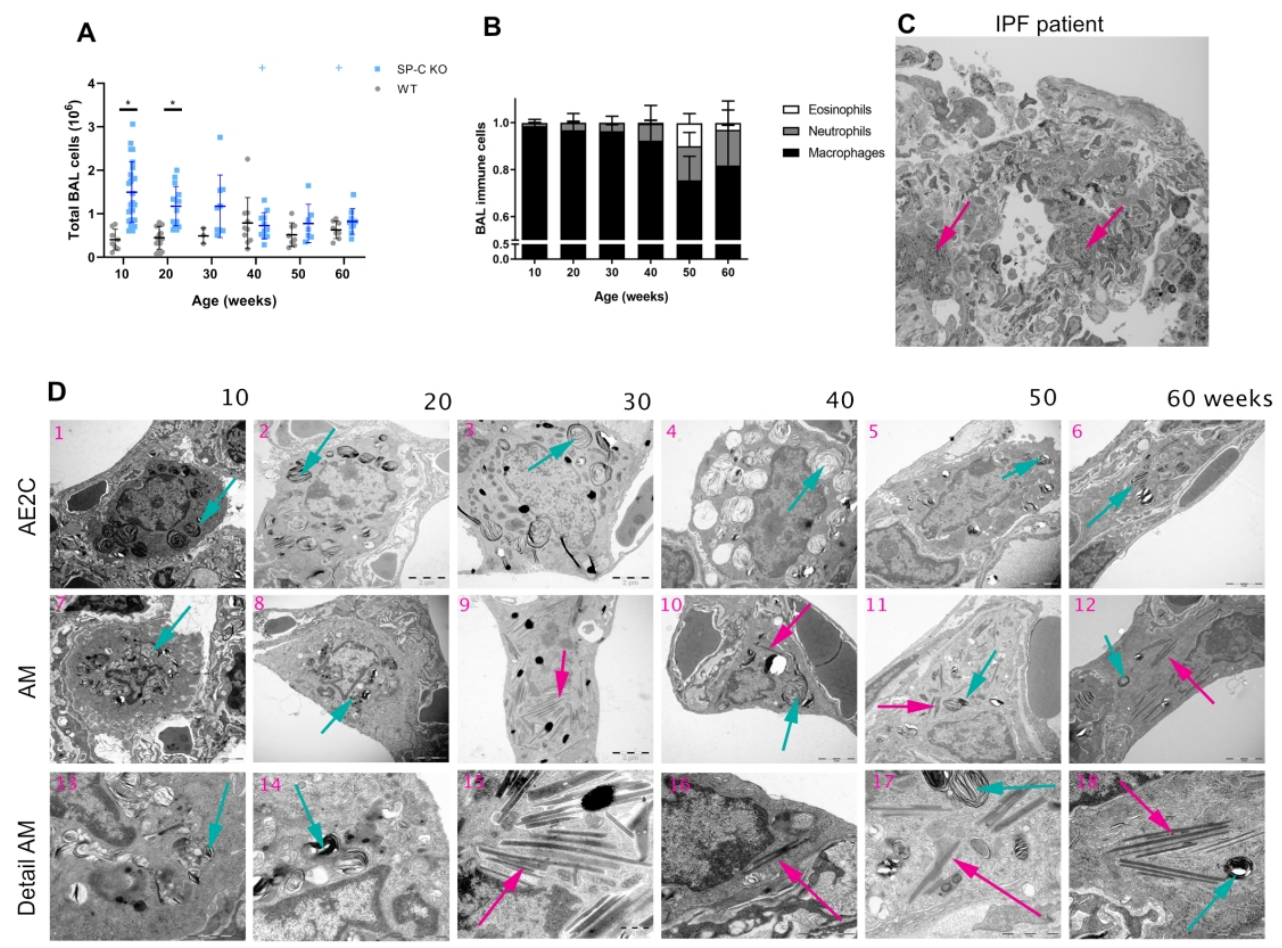

Figure 4. SP-C deficiency alters the innate immune system of the lung. A) Total BALF cell count assessed in SP-C KO and healthy 129Sv mice. B) Relative quantification of leukocyte subpopulations in BALF cells of SP-

C KO mice. C) Electron-microscopic micrograph of an IPF lung demonstrates the presence of intraparenchymal macrophages being loaded with electron-dense crystals (pink arrow). D) Representative electron-microscopic imaging of SP-C KO lungs over age demonstrates unaltered AEC2 morphology with physiologically shaped lamellar bodies (green arrow) (F1-6) and electron-dense intracellular inclusions with cleft formation in lung macrophages (pink arrow) (F7-12). Onset of crystal formation starts at 30 weeks of age. Detailed structural morphology of the lamellar-body-like inclusions and electron-dense clefts is provided on high-magnification micrographs (F13-18). Mean $\pm S D, n \geq 6$; horizontal black lines with an asterisk (*) represents a statistical difference $\mathrm{p}<0.05$ between SP-C KO vs Healthy within age groups. Statistical differences over age are represented in blue for the SP-C KO group and in grey for the healthy controls. $+\mathrm{p}<0.05$ vs. 10 weeks.

$204 \times 152 \mathrm{~mm}(300 \times 300$ DPI $)$ 

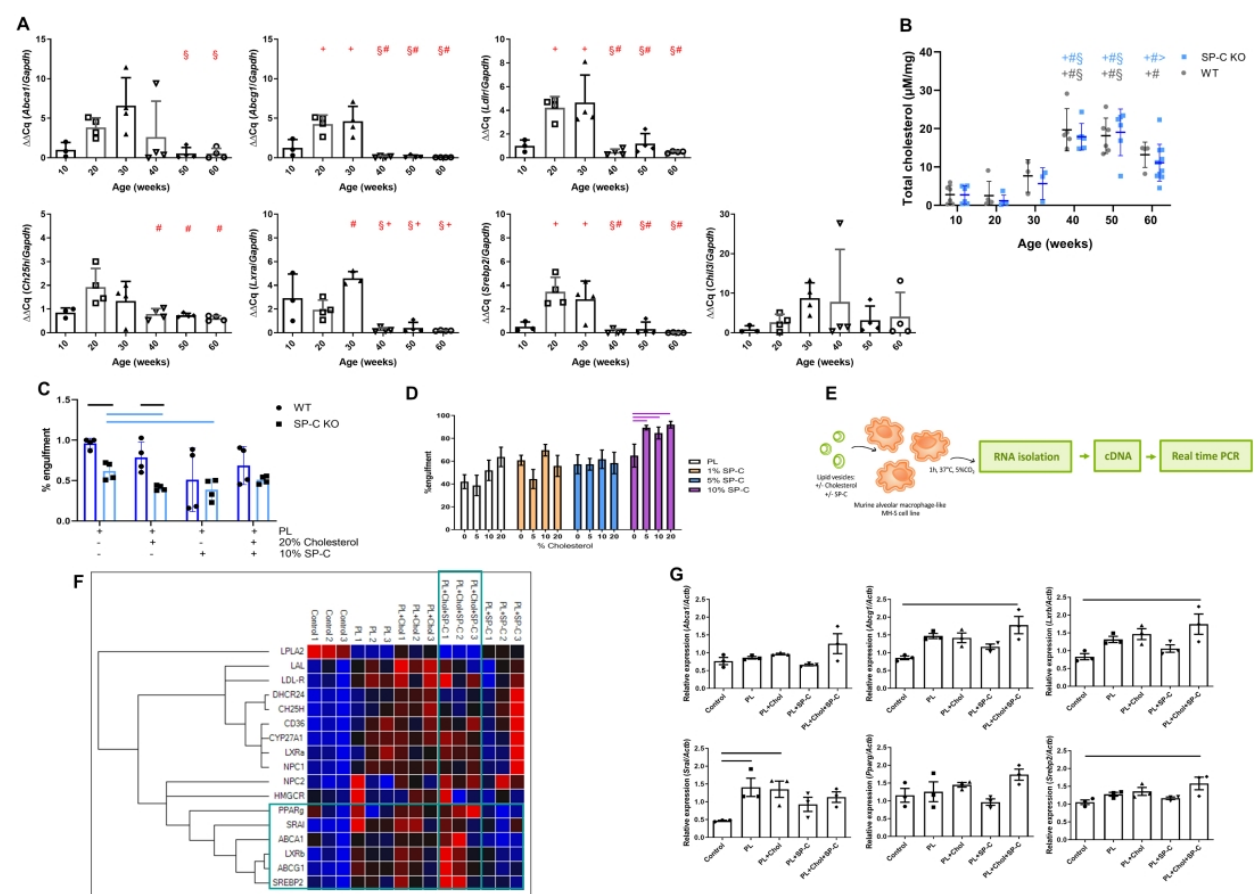

Figure 5. Absence of SP-C leads to impaired cholesterol metabolism in alveolar macrophages. A) RT-PCR gene expression analysis of ATP binding cassette A1 (Abca1), ATP binding cassette G1 (Abcg1), cholesterol25-hydroxylase (Ch25h), LDL receptor (Ldlr), liver X receptor alpha (Lxra), sterol response element binding protein 2 (Srebp2) and chitinase like 3 or Ym1 (Chil3) in BALF cells. Normalized by Gapdh. B) Total Cholesterol quantification in SP-C KO and healthy 129Sv lungs per $\mu \mathrm{g}$ lung tissue at week 10-60. C) Fluorescent-lipid uptake by alveolar macrophages as percentage of engulfment, measure by FACS detection of fluorescent BAL cells from WT or SP-C KO mice. Macrophages were exposed to $0.25 \mu \mathrm{g}$ of labeled phospholipid per 105 cells, with/without cholesterol and/or SP-C. Black horizontal lines represents $p<0.05$ between WT vS KO using a t-test, light blue horizontal lines represents $p<0.05$ when comparing different vesicle composition within the SP-C KO group using an ANOVA. D) MH-S cells, alveolar macrophage-like mouse cell line, were exposed to lipid vesicles laden with fluorescent cholesterol and/or SP-C and lipid uptake was measure in FACS as explained before. E) In another set of experiments macrophages exposed to vesicles with different composition during $1 \mathrm{~h}$ were collected for RNA isolation and RT-PCR analysis of expression of genes related to cholesterol metabolism and transport. F) Representative heat map of relative expression of the different genes using clustering by targets (right) and samples ordered by type (top). The green rectangle shows different targets up-regulated in the samples containing cholesterol and SP-C in comparison to samples containing only cholesterol or SP-C. G) Relative gene expression ( $\Delta \Delta$ Cq, normalized by Actb) in the different samples ( $n=6$ per group) of the most interesting upregulated genes from the heat map, Pparg, SraI, Abca1, Lxrb, Abcg1, and Srebp2). Mean \pm SD, $n \geq 6$; horizontal black lines with an asterisk

(*) represents a statistical difference $p<0.05$ between SP-C KO vs Healthy within age groups. Statistical differences over age are represented in blue for the SP-C KO group and in grey for the healthy controls. $+p<0.05$ vs. 10 weeks; \#p<0.05 vs. 20 weeks; $\S p<0.05$ vs. 30 weeks; $<p<0.05$ vs. 40 weeks; >p<0.05 vs. 50 weeks. 
A

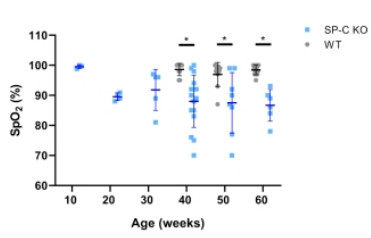

D
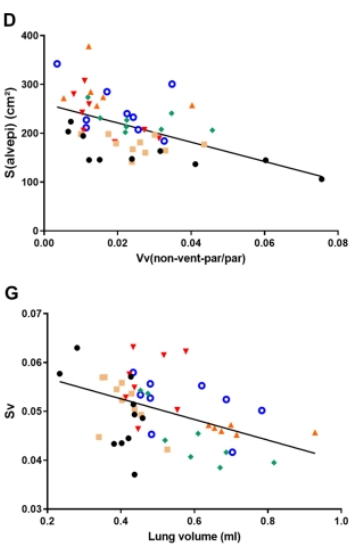
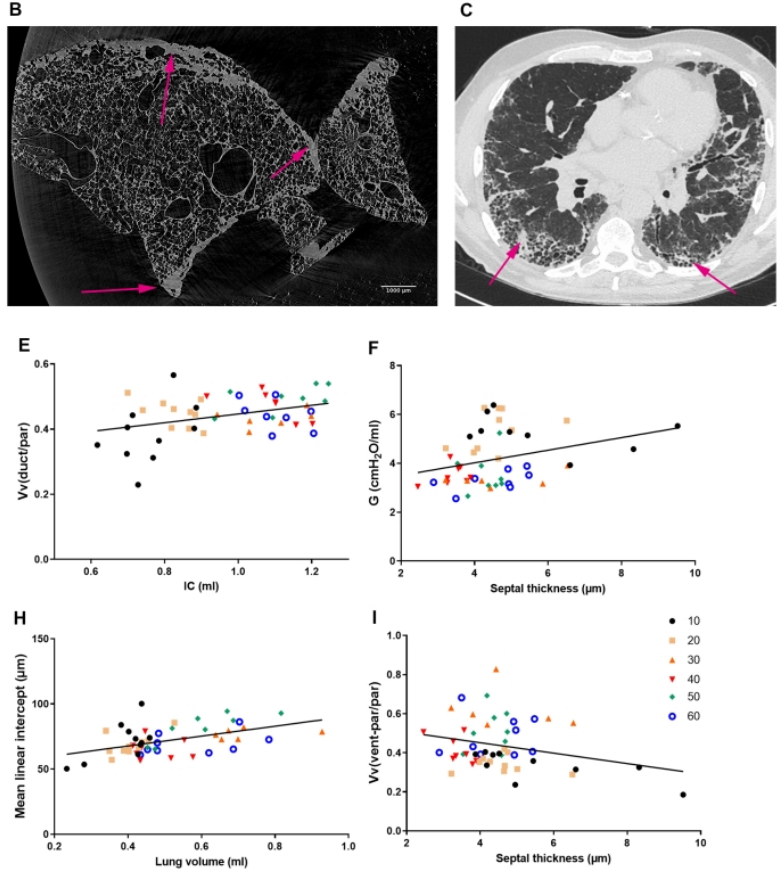

Figure 6. Structure-function relationship in the SP-C KO lung. A) Peripheral arterial oxygen saturation ( $\mathrm{SpO} 2$ ) was measured at PEEP $3 \mathrm{cmH} 2 \mathrm{O}$ before subsequent ventilation protocol was started in SP-C KO and healthy 129Sv mice; B) $\mu C T$ imaging of a fixed SP-C KO lung shows distinct parenchymal lesions predominating in the subpleural compartments (pink arrow); C) HR-CT imaging of a 75-year-old IPF patient. The pathology impresses with reticular septal thickening, honeycomb-cysts, traction bronchiectasis, and tissue consolidation (pink arrow) in the means of UIP pattern. The pathology predominates in the subpleural regions and localizes in the direct neighborhood of over distended lung parenchyma. Statistically significant correlation of structural and mechanical parameters over the whole study period ( $\bullet 10$ weeks, $\mathbf{2} 20$ weeks, $\Delta 30$ weeks, $\mathbf{} 40$ weeks, 50 weeks, $\circ 60$ weeks). D) Negative correlations between alveolar surface and non-ventilated parenchyma volume fraction by stereological analysis, and E) surface density and absolute lung volume. F) Proportional relationship of ductal volume fraction and inspiratory capacity acquired by FlexiVent. G) Positive correlation of mean linear intercept and absolute lung volume as independently determined structural parameters. H) Tissue damping and septal thickness exhibit a positive structurefunction relationship whereas I) ventilated parenchyma volume fraction and septal thickness correlate inversely. Mean $\pm S D, n \geq 6$; horizontal black lines with an asterisk $\left(^{*}\right)$ represents a statistical difference $\mathrm{p}<0.05$ between SP-C KO vs Healthy within age groups. 


\title{
Online Supplementary Material
}

\section{Air Space Distension Precedes Spontaneous Fibrotic Remodeling and Impaired} Cholesterol Metabolism in the Absence of Surfactant Protein C

\author{
Jannik Ruwisch ${ }^{1,2^{*}}$, Kirsten Sehlmeyer ${ }^{1,2^{*}}$, Nuria Roldan ${ }^{3,4}$, Begoña Garcia-Alvarez ${ }^{4}$ Jesus Perez- \\ Gil $^{4}$, Timothy E. Weaver ${ }^{5}$, Matthias Ochs ${ }^{1,2,6}$, Lars Knudsen ${ }^{1,2}$ and Elena Lopez-Rodriguez ${ }^{1,2,6 \#}$ \\ ${ }^{1}$ Institute of Functional and Applied Anatomy, Hannover Medical School, Hannover, Germany
}

${ }^{2}$ Biomedical Research in Endstage and Obstructive Lung Disease Hannover (BREATH), Member of the German Centre for Lung Research (DZL), Hannover, Germany

${ }^{3}$ Alveolix AG and ARTORG Center, University of Bern, Bern, Switzerland

${ }^{4}$ Biochemistry and Molecular Biology Department, Faculty of Biology, and Research Institute “Hospital 12 de Octubre", Complutense University Madrid, Madrid, Spain

\begin{abstract}
${ }^{5}$ Cincinnati Children's Hospital Medical Center and the University of Cincinnati College of Medicine, Cincinnati, Ohio
\end{abstract}

${ }^{6}$ Institute of Vegetative Anatomy, Charité - Universitaetsmedizin Berlin, Berlin, Germany

*both authors contributed equally to this work

\# Correspondence: elena.lopez-rodriguez@charite.de, Charite Universitatsmedizin zu Berlin, Institute of Vegetative Anatomy, Philippstr. 12, 10115 Berlin, +4930450528037 


\section{Supplementary Material and Methods}

\section{Animal model}

SP-C deficient mice were introduced before (1) and obtained with permission from Cincinnati children's hospital (Cincinnati, Ohio). 129Sv healthy mice, which served as control group, were acquired from Charles River GmbH (Sulzfeld, Germany). Both male and female mice were divided in 6 groups per cohort, housed according to common European directive 2010/63 (ETS 123) conditions and raised for 10, 20, 30, 40, 50 or 60 weeks, respectively. All animal experiments were carried out according to the German "TierschutzGesetz" (TierSchG, 2013) and EU-Directive 2012/63, approved by the authorities of Lower Saxony (LAVES, Niedersächsisches Landesamt für Verbraucherschutz und Lebensmittelsicherheit) with number 16/2245. Presence of relevant murine pathogens was ruled out according to FELASA recommendations (2014).

\section{Vascular perfusion fixation}

In order to preserve the intra-alveolar space including alveolar surface lining, air-filled alveolar spaces and open capillaries lungs were fixed via the vasculature in accordance to the ATS/ERS consensus statement (2) and detailed in supplementary methods. Lung volume (V(lung)) was determined by fluid displacement according to the Archimedes principle as mean of three repetitive measurements and systemic uniform random sampling of lung tissue was performed as described before (3).

\section{Bronchoalveolar lavage}

Following analysis of alveolar dynamics, minimum 5 mice per group underwent bronchoalveolar lavage. After animals were euthanized by exsanguination, the trachea was cannulated, a thoracotomy was performed, and the pulmonary vasculature was rinsed via the right ventricle with $0.25 \%$ heparin in $0.9 \% \mathrm{NaCl}$. Subsequently, three aliquots of $\mathrm{NaCl}$ were actively instilled until the lungs were fully 
inflated and the liquid was withdrawn and collected on ice. Afterwards, lungs were excised, isolated from non-lung tissue and frozen in cryo-tubes in liquid nitrogen for later protein or RNA isolation. Finally, BALF was separated from the pulmonary alveolar cells by centrifugation at $300 \mathrm{~g}$ at $4^{\circ} \mathrm{C}$ for 10 minutes and the cell free supernatant was frozen at $-80^{\circ} \mathrm{C}$. The pellet was treated with $1 \mathrm{ml}$ red blood cell lysis buffer (1,5mM NH 4 CL (Merck KGaA, Darmstadt, Germany) 100 $\mathrm{MM} \mathrm{KHCO}_{3}$ (Merck KGaA, Darmstadt, Germany) and 340nM EDTA (SERVA Electrophoresis GmbH, Heidelberg, Germany)) prior to resuspension in $100 \mu \mathrm{l}$ PBS.

\section{Cell countings}

An automated T10 cell counter (Bio-Rad Laboratories, Munich, Germany) was employed to quantify the number and viability of cells with trypan blue. For each group, 3-5 BALF samples were analyzed for cell differentials. Following immobilization by cytospinning, cytospots were stained with Quick-Diff. (Medion Diagnostics, 7440 SW 50 Terrace Suite 110, Miami, FL 33155) accordingly to the protocol. Cell counting events of macrophages, neutrophils and eosinophils were set relative to the total cell quantity per series of randomly generated images, employing a ZEISS Axiophot microscope (Zeiss, Oberkochen, Germany).

\section{Lung mechanic and function measurements}

All animals were weighed and anesthetized via intraperitoneal injection of $80 \mathrm{mg} / \mathrm{kg}$ ketamine and $5 \mathrm{mg} / \mathrm{kg}$ xylazine in $0.9 \%$ sodium chloride. Following tracheotomy, mice were connected to a small animal ventilator (FlexiVent, SCIREQ, Montreal, QC, Canada) and mechanical ventilation was performed as described previously (4) and detailed in supplementary methods. Following a short period of normal mechanical ventilation at a positive end expiratory pressure (PEEP) of $3 \mathrm{cmH}_{2} \mathrm{O}$, inspiratory capacity (IC) was measured applying a total lung capacity perturbation that simultaneously served as recruitment maneuver inflating the lungs up to $30 \mathrm{cmH}_{2} \mathrm{O}$. Perturbations based on forced oscillation technique (FOT) were repeated every 10 seconds for 100 seconds at PEEP of $3 \mathrm{cmH}_{2} \mathrm{O}$ and input impedance was assessed. Tissue elastance $(\mathrm{H})$, tissue damping $(\mathrm{G})$ and hysteresivity (eta) were subsequently calculated by fitting the measurements to the constant phase model (5). Three 
pressure-volume (PV) loops were recorded to determine mean quasi-static compliance (Cst) at a PEEP of $3 \mathrm{cmH}_{2} \mathrm{O}$. FOT perturbations were repeated at PEEP of 1 and $6 \mathrm{cmH}_{2} \mathrm{O}$ and $\mathrm{H}$ was computed, analogously. Afterwards, 5-10 animals per group underwent bronchoalveolar lavage (BAL), while minimum 6 lungs of each group were inflated with $30 \mathrm{cmH}_{2} \mathrm{O}$ and airway opening pressure was steadily reduced to a plateau of $5 \mathrm{cmH}_{2} \mathrm{O}$. At a defined pressure of $5 \mathrm{cmH}_{2} \mathrm{O}$, the trachea was ligated, and the animal was disconnected from the FlexiVent. Oxygen saturation in percentage of functional arterial hemoglobin was determined during normal mechanical ventilation at PEEP $3 \mathrm{cmH}_{2} \mathrm{O}$ before initiating the perturbation protocol under use of a rodent oximeter (MouseOx Plus, Starr Life Sciences Corp., US).

\section{Vascular perfusion fixation}

In order to preserve the intra-alveolar space including alveolar surface lining, air-filled alveolar spaces and open capillaries lungs were fixed via the vasculature in accordance to the ATS/ERS consensus statement (2). After inflating the lungs at a pressure of $5 \mathrm{cmH}_{2} \mathrm{O}$, a median laparotomy was performed. Caudal vena cava was depicted and abdominal aorta was incised for exsanguination before flushing the pulmonary vasculature via the cannulated caudal vena cava with $0.9 \%$ sodium chloride and $0.25 \%$ heparin at a constant pressure of $25-30 \mathrm{cmH}_{2} \mathrm{O}$. Afterwards, the fixative $(1.5 \%$ paraformaldehyde, 1.5\% glutaraldehyde, in 0.15 M HEPES buffer) was injected. Subsequently, a median thoracotomy was performed. Lung lobes and mediastinal organs were excised in toto and further emerged in fixative for 24 hours at $4^{\circ} \mathrm{C}$. Finally, the primary bronchi were ligated, and the inflated lung lobes were separated from non-lung tissue. Lung volume (V(lung)) was determined by fluid displacement according to the Archimedes principle as mean of three repetitive measurements and systemic uniform random sampling of lung tissue was performed as described before (3).

\section{Design-based stereology}

Design-based stereology is the gold-standard for quantitative lung structure analysis based on histological images enabling profound mathematical inference from 2D sections about 3D geometrical bodies, as which microarchitectural compartments of the distal lung have to be considered (6). 
Stereological analysis was based on micrographs acquired at 20x magnification by a slide scanner (Axio Scan.Z1 (Carl Zeiss AG, Oberkochen, Germany) and subsequent automatic subsampling performed by the stereology Visiopharm software (Visiopharm, Horsholm, Denmark). A stereology tool (STEPanizer@, Bern, Switzerland) was employed for definitive stereological morphometry. A point grid was chosen as test system for volume estimation. Securing sufficient stereological precision, the number of test points was adjusted to a minimum of 200 to 300 counting events per parameter per lung (7). A counting event was defined as match of a structure of interest (SOI) with the test probe. At $5 x$ magnification, volume fractions of parenchyma ( $\mathrm{Vv}(\mathrm{par} / \mathrm{lung}))$ and non-parenchyma ( $\mathrm{Vv}$ (nonpar/lung)) were obtained. Parenchyma was defined as lung tissue enabling gas exchange, comprising septa and airspaces, and was differentiated in ventilated $(\mathrm{Vv}$ (ventpar/par)) and non-ventilated parenchyma ( $\mathrm{Vv}($ non-vent/par)). Pleura, conducting airways and large vessels with the surrounding connective tissue were defined as non-parenchyma. Volume densities of ductal airspaces ( $\mathrm{Vv}$ (duct/par), alveolar airspaces ( $\mathrm{Vv}(\mathrm{alv} / \mathrm{par})$ and alveolar septa $(\mathrm{Vv}(\mathrm{sept} / \mathrm{par}))$ were determined at 20x magnification within ventilated parenchyma. Herein, an additional test system consisting of 4 linepairs was utilized for counting intersections of test probes and alveolar surface. All analyzed parameters for lung structure regarding fibrosis were chosen according to recommendations from Ochs and Mühlfeld (7) for stereology in pulmonary fibrosis. A detailed description of investigated parameters and corresponding test systems is presented in table 1.

Volume densities (e.g. Vv(par/lung)) were calculated by dividing the number of points hitting the SOI (PSOI) by the number of points hitting the reference space, e.g. total lung.

$$
\operatorname{Vv}(\text { par/ung })=\sum[\text { Ppar }] / \sum[\text { Ppar+Pnon-par }]
$$

Multiplication of the volume fraction with total lung volume provided absolute volumes of each SOI

$$
\text { (e.g. } \mathrm{V}(\text { par,lung })) \text { : } \quad \mathrm{V}(\text { par,lung })=\mathrm{Vv} \text { (parlung })^{*} \mathrm{~V}(\text { lung }) \text {, }
$$

Analogous calculations were performed for parenchymal components, e.g. alveolar airspaces: 


$$
\begin{gathered}
\mathrm{Vv}(\text { alv/ven-tpar })=\sum[\text { Palv }] / \sum[\text { Pvent-par }], \\
\mathrm{V}(\text { alv,vent-par })=\mathrm{Vv}(\text { alv/vent-par })^{*} \mathrm{~V}(\text { vent-par,lung }),
\end{gathered}
$$

Intersection countings (intersect) were utilized in combination with the length per point of the test system (l(p)) to estimate the alveolar surface density of ventilated parenchyma. The calculated absolute volume describes the alveolar surface contributing to pulmonary gas exchange:

$$
\begin{aligned}
& \text { Sv(alv/vent-par })=\left(2^{*} \sum[\text { intersect }]\right) /\left(1(p)^{*} \sum[\text { Pvent-par }]\right. \\
& S(\text { alv,lung })=S v(\text { alv } /(\text { vent-par }))^{*} \mathrm{~V}(\text { vent-par,lung }),
\end{aligned}
$$

Septal thickness was computed as follows:

$$
\text { Septal thickness }=\operatorname{Vv}(\text { sept } / \text { par }) / \operatorname{Sv}(\text { alv/par })^{*} 2 \text {, }
$$

Length of test line $(1(1))$, number of lines per point $(n(l(p)), p(a l v)$ and $n($ intersect) were utilized to calculate the mean linear intercept length:

$$
\text { Mean linear intercept }=2^{*} 1(1)^{*} \mathrm{n}(\mathrm{lp})^{*} \mathrm{P}(\mathrm{alv})^{*} \mathrm{n}(\text { intersect }) \text {, }
$$

Volume weighted mean volume $\left(\bar{v}_{\mathrm{v}}\right)$ was assessed for rather detailed alveolar size and heterogeneity analysis (8). $\bar{v}_{\mathrm{v}}$ is independent of absolute alveolar quantity and is based on point sampled intercept length (PSI) (9). The PSI measures the diameter of 3D, isotropic orientated SOI, superimposing a point grid and a random orientated ruler on orcein stained 2D lung sections. Alveolar spaces were defined as SOI. As alveoli miss a clear anatomical limitation in the area of the air entrance, missing borders were artificially constructed as previously described (10) by closing the alveolar entrance with a straight line. Orcein staining accentuated the elastic fibers at the alveolar entrance rings. FOV (fields of view) were obtained at 20x magnification using an Axioskop light microscope DM6000B (Leica, Wetzlar, Germany) attached to a digital camera DP72 (Olympus, Hamburg, Germany). Subsequent random subsampling was performed employing a NewCast System (Visiopharm, Horsholm, Denmark) under 
use of Visiopharm software. A positive counting event was defined by the point grid hitting the alveolar space and PSI measurement was conducted as determination of the distance between the two intersections of alveolar boundaries and test ruler. The resulting PSI length of each counting event were utilized to calculate the $\bar{v}_{\mathrm{v}}$ of every analyzed alveolus following(11):

$$
\bar{v}_{\mathrm{v}}=\pi / 3^{*} \mathrm{PSI}^{3}
$$

\section{Histological sections and staining}

Tissue slices were embedded into hydroxyethylmethacrylate (Technovit 8100, Kulzer Heraeus, Wehrheim, Germany). For further design-based stereology on light microscope level, minimum 3 tissue specimen per lung were cut in sections of $1.5 \mu \mathrm{m}$ thickness and stained with $0.1 \%$ toluidine blue or $0.2 \%$ orcein. Simultaneously, lung cubes were sampled randomly for representative electron microscope (EM) imaging. Cubes were embedded in Epon (Serva, Heidelberg, Germany), while 1\% osmium tetroxide (EMS, Hatfield, PA) and 4\% uranyl acetate (Serva, Heidelberg, Germany) served as contrast agent. Remaining tissue slices were embedded in paraffin and stained with a Masson-Goldner staining kit (Merck, Darmstadt, Germany) for detection of connective tissue (green). Immunostaining of human tissue sections is detailed in supplementary methods.

\section{Immunohistochemistry}

Fixation of human lungs was performed in $4 \%$ formaldehyde. Afterwards lung probes were embedded in formalin and serial sections ( $3 \mu \mathrm{m}$ thickness) were cut. The latter were stained with hematoxylin \& eosin. AP-fast red kit (Zytochem systems, Berlin, Germany) was employed in accordance to the manufacturer's instructions for immunohistochemical localization of pro-SP-C (Seven Hills). Microwaving the sections in 10mM Sodium citrate buffer, $\mathrm{pH} 6.0$ was utilized for antigen retrieval. Hemalaun was used for counter-staining. 


\section{Hydroxyproline assay}

Hydroxyproline content was measured in accordance to the protocol established by Reddy and Enwemeka (12). Approximately $40 \mathrm{mg}$ of lung tissue were homogenized in $200 \mu \mathrm{l}$ ultrapure water and total protein concentration was measured by a BCA assay (Pierce ${ }^{\circledR}$ BCA Protein Assay Kit, Thermo Scientific, Rockford, IL, USA). Lung homogenate was dried overnight at $65^{\circ} \mathrm{C}$ and hydrolyzed in $6 \mathrm{~N}$ $\mathrm{HCl}$ at $100^{\circ} \mathrm{C}$ for 24 hours. After neutralization with $6 \mathrm{~N} \mathrm{NaOH}, 25 \mu \mathrm{l}$ of sample were dried at $65^{\circ} \mathrm{C}$. Next, Chloramine T reagent was applied for oxidation at room temperature. For colorimetric reaction equal volumes of Ehrlich's reagent were added and samples were heated up to $65^{\circ} \mathrm{C}$ for 20 minutes. Subsequently, absorbance was measured at 570nm and hydroxyproline concentration was calculated according to a standard row.

\section{Cholesterol assay}

Representative frozen lung pieces were initially weighed and stored in polypropylene tubes. Chloroform $(66,67 \%)$ and methanol $(33,33 \%)$ serving as organic solvent for cholesterol drainage, was added and tissue homogenization was performed. After centrifugation $(15.000 \mathrm{~g}$, 10minutes) total cholesterol concentration was quantified following instructions of "Total Cholesterol Assay Kit (Colorimetric)" (Cell Biolabs, Inc., San Diego, CA 92126). Esterified cholesterol was released for quantification using cholesterol esterase, being included in the kit. Total cholesterol amount was set relative to absolute mass of homogenized lung specimen.

\section{Engulfment of cholesterol-laden lipid vesicles with or without SP-C}

To analyze the engulfment of lipid vesicles by alveolar macrophages, cells incubated with different types of fluorescently labeled vesicle were analyzed by flow cytometry using a MACSQuant 10 analyzer (Miltenyi Biotech, Cologne, Germany). 
The phospholipid fraction (PL) of porcine pulmonary surfactant (13) and proteins in Chl/MeOH were mixed in the indicated proportions and labeled with $5 \mathrm{wt} \%$ of TopFluor cholesterol (23(dipyrrometheneboron difluoride)-24-norcholesterol, Avanti Polar Lipids) in Chl/MeOH 2:1 v/v. Samples were protected from light to avoid fluorescence bleaching. Solvents were evaporated in a fume hood at $40^{\circ} \mathrm{C}$ and samples maintained in a vacuum oven at $50^{\circ} \mathrm{C}$ overnight. Lipid films were hydrated to $0.5 \mathrm{mg} / \mathrm{ml}$ with $50 \mathrm{mM}$ Tris $\mathrm{pH} 7.0150 \mathrm{mM} \mathrm{NaCl}$ at $60 \mathrm{oC}$ for $1 \mathrm{~h}$ at $1400 \mathrm{rpm}$ in a Thermo-Shaker TS100C (BioSan, Riga, Latvia).

For the cytometry experiments, $10^{5}$ cells/well in $90 \mu \mathrm{l}$ PBS were administrated $10 \mu \mathrm{l}$ lipid suspensions and incubated at room temperature for the indicated times and lipid concentrations (see Results). Cells were re-suspended by pipetting before and after lipid addition and just prior flow cytometry measurements. At least 10.000 events were recorded per sample. Vesicle engulfment was detected in the FITC channel and quantified by stablishing a threshold according to the fluorescence detected from non-treated cells. Data were analyzed with MacsQuant software (Miltenyi Biotec; Cologne, Germany) and GraphPad Prism 5 (La Jolla, CA, USA).

\section{Real time - PCR}

RNA was isolated from homogenized, post-lavage lungs following ISOLATE II RNA Mini Kit instructions (ISOLATE RNA Mini Kit, Bioline GmbH, Luckenwalde, Germany). RNA quantity was determined by spectrophotometry at 260nm, employing a nanodrop 2000 (NANODROP 2000, Spectrophotometer, Thermo Scientific). $1 \mu \mathrm{g}$ of RNA per sample was used for reverse transcription following instructions of the iScript ${ }^{\mathrm{TM}}$ cDNA Synthesis Kit (Bio-Rad Lab). cDNA synthesis was performed in a Thermal Cycler (CFX96TM, Bio-Rad Laboratories, Munich, Germany). Subsequent RTPCR was performed with iTaq Universal SYBR Green Supermix (Bio-Rad Laboratories, Munich, Germany), mixing 100ng of primer with 50ng cDNA. An initial 3 min denaturation phase at $95^{\circ} \mathrm{C}$ served as activation step for the antibody repressed iTaq polymerase. In the annealing and extension phase, temperature was decreased to $59^{\circ} \mathrm{C}$ for 30 s for 40 cycles under employment of a CFX96 Thermal Cycler 
(CFX96TM, Bio-Rad Laboratories, Munich, Germany). Primers were designed with the application PrimerBlast (National Center for Biotechnology Information, U.S. National Library of Medicine, USA) and synthetized by Eurofins Genomics (Ebersberg, Germany). Primer sequences are shown in detail in table 2. Quantification of the amplification data was assessed in the early exponential stage of the replication phase and normalized rate of gene expression $(\Delta \Delta \mathrm{Cq})$ was chosen for RT-PCR data representation, relating amplification data to reference gene amplification and control sample (week 10). Delta delta $\mathrm{Ct}(\Delta \Delta \mathrm{Ct})$ method is a direct comparison of $\mathrm{Ct}$ values between the target gene and the reference gene (b-ACTIN, GAPDH). Relative quantification involves the choice of a calibrator sample (week 10). Firstly, the $\Delta \mathrm{Ct}$ between the target gene and the reference gene is calculated for each sample (for the unknown samples and also for the calibrator sample). $\Delta \mathrm{Ct}=\mathrm{Ct}_{\text {target }}-\mathrm{Ct}_{\text {reference gene. Then the }}$ difference between the $\Delta \mathrm{Ct}$ of the unknown and the $\Delta \mathrm{Ct}$ of the calibrator is calculated, giving the $\Delta \Delta \mathrm{Ct}$ value: $\Delta \Delta \mathrm{Ct}=\left(\mathrm{Ct}_{\text {target }}-\mathrm{Ct}_{\text {reference }}\right)_{\text {calibrator }}-\left(\mathrm{Ct}_{\text {target }}-\mathrm{Ct}_{\text {reference }}\right)_{\text {sample. }}$ Data is presented as Mean $+\mathrm{SD}$; Group size $n=3-5$.

\section{Statistical analysis}

Graphs and statistical analysis were conducted with GraphPad Prism 6.0 (GraphPad Software, San Diego, CA, USA). Data is presented as scattered dot plot (with mean+SD), bar chart (mean + SD) or boxplot. Statistical differences between controls and $\mathrm{KO}$ are presented in the text, differences within control or SP-C KO groups are presented in the graphs and effect differences between group (genotype) versus time are presented in supplementary table 3. Multiple group comparisons were analyzed by a one-way ANOVA test and corrected with a Bonferroni post-hoc analysis comprising a 95\% confidence interval. Mixed-effects model was used to compare genotype (group) versus time. Correlation analyses were performed applying the Spearman test and linear regression using the software SPSS (IBM, Ehningen, Germany). Overall, p-values $<0.05$ were considered statistically significant. 


\section{Results}

Age related changes in lung mechanics in healthy $129 \mathrm{~Sv}$ mice

Tissue elastance measurements pointed towards a pressure dependent recruitment of airspaces resulting in lower tissue elastance at higher PEEP (Suppl. Figure 1A). In fact, an increase in PEEP was continuously sufficient to significantly lower tissue elastance at every studied age in the healthy $129 \mathrm{~Sv}$ cohort. When comparing age groups, tissue elastance exhibited a steady decline with increasing age at a PEEP of 1 and $3 \mathrm{cmH} 2 \mathrm{O}$ whereas the decrease with age was rather neglectable at a PEEP of $6 \mathrm{cmH} 2 \mathrm{O}$.

\section{Age related changes in lung morphology in healthy $129 \mathrm{~Sv}$ mice}

Histological sections (Suppl. Figure 2A) showed minor changes of lung general morphology during the 60 weeks' time course in healthy 129Sv mice.

\section{Age-dependent analysis of tissue composition and connective-tissue protein gene expression in} healthy 129Sv mice.

Masson-Goldner stained lung sections showed neither increased of interstitial collagen deposition nor fibrotic lesions (Suppl. Figure 3A). Instead, homogeneously ventilated lung parenchyma was depicted. Likewise, hydroxyproline quantification demonstrated no agedependent alterations between week 40-60 (Suppl. Figure 3B). In contrast, gene expression analysis of connective-tissue related genes revealed a significant age-related expression pattern: expression of the investigated genes Col1a1, Col2a1, Col3a1, Eln and Fn initially decreased by age (Suppl. Figure 3C-3G). Minimum expression rates were seen at 40 weeks of age. While elastin expression remained constant at a basal expression level, transcription rate of matrix fibers contributing to lung stiffness like collagen3a1 and fibronectin showed a significant increase at week 60 compared to week 40 , what may contribute to the age-related parenchymal restructuration, which was seen before. 
Age-dependent analysis of BALF cells in healthy 129/Sv mice.

Healthy 129 Sv mice showed unaltered BALF cell quantity over the whole study timeframe

(Figure 4A). Therein, only neglectable amounts of neutrophils were detected (Suppl. Figure 4A).

Age-dependent analysis of expression of genes related to the cholesterol metabolism in healthy 129/Sv mice.

Gene expression analysis of cholesterol metabolism related genes generally showed steady expression level over age. However, a significant age dependent decrease in gene expression between week 30 and 40 was noted for Abcg1, Ch25h and Srebp2 (Supp. Figure 5A). Correspondingly, total lung cholesterol amount was significantly increased from week 30 to 40 (Figure 5B). 


\section{Supplementary References}

1. Glasser SW, Burhans MS, Korfhagen TR, Na C-L, Sly PD, Ross GF, Ikegami M, Whitsett JA. Altered stability of pulmonary surfactant in SP-C-deficient mice. Proc Natl Acad Sci 2001;98:6366-6371.

2. Hsia CCW, Hyde DM, Ochs M, Weibel ER. An Official Research Policy Statement of the American Thoracic Society/European Respiratory Society: Standards for Quantitative Assessment of Lung Structure. Am J Respir Crit Care Med 2010;181:394-418.

3. Tschanz S, Schneider JP, Knudsen L. Design-based stereology: Planning, volumetry and sampling are crucial steps for a successful study. Ann Anat - Anat Anzeiger 2014;196:3-11.

4. Beike L, Wrede C, Hegermann J, Lopez-Rodriguez E, Kloth C, Gauldie J, Kolb M, Maus UA, Ochs M, Knudsen L. Surfactant dysfunction and alveolar collapse are linked with fibrotic septal wall remodeling in the TGF- $\beta 1$-induced mouse model of pulmonary fibrosis. Lab Investig 2019; at <https://doi.org/10.1038/s41374-019-0189-x>.

5. Hantos Z, Daroczy B, Suki B, Nagy S, Fredberg JJ. Input impedance and peripheral inhomogeneity of dog lungs. J Appl Physiol 1992;72:168-178.

6. Ochs M, Mühlfeld C. Quantitative microscopy of the lung: a problem-based approach. Part 1: basic principles of lung stereology. Am J Physiol Cell Mol Physiol 2013;305:L15-L22.

7. Mühlfeld C, Ochs M. Quantitative microscopy of the lung: a problem-based approach. Part 2: stereological parameters and study designs in various diseases of the respiratory tract. $A m \mathrm{~J}$ Physiol Cell Mol Physiol 2013;305:L205-L221.

8. Knudsen L, Weibel ER, Gundersen HJG, Weinstein F V, Ochs M. Assessment of air space size characteristics by intercept (chord) measurement: an accurate and efficient stereological 
approach. J Appl Physiol 2009;108:412-421.

9. Sorensen FB. Stereological estimation of the mean and variance of nuclear volume from vertical sections. J Microsc 1991;162:203-229.

10. Massaro GD, Massaro D. Formation of alveoli in rats: postnatal effect of prenatal dexamethasone. Am J Physiol Cell Mol Physiol 1992;263:L37-L41.

11. Brændgaard H, Gundersen HJG. The impact of recent stereological advances on quantitative studies of the nervous system. J Neurosci Methods 1986;18:39-78.

12. Kesava Reddy G, Enwemeka CS. A simplified method for the analysis of hydroxyproline in biological tissues. Clin Biochem 1996;29:225-229.

13. Taeusch HW, Bernardino de la Serna J, Perez-Gil J, Alonso C, Zasadzinski JA. Inactivation of pulmonary surfactant due to serum-inhibited adsorption and reversal by hydrophilic polymers: experimental. Biophys J 2005;89:1769-79. 


\section{Supplementary Figure Legends}

Suppl. Figure 1 Age related changes in lung mechanics in healthy 129Sv mice. E) Tissue elastance at PEEP $1 \mathrm{cmH}_{2} \mathrm{O}$ (black), $3 \mathrm{cmH}_{2} \mathrm{O}$ (grey) and $6 \mathrm{cmH}_{2} \mathrm{O}$ (white); Mean $\pm \mathrm{SD}, \mathrm{n} \geq 5$.

Suppl. Figure 2. Age related changes in lung morphology in healthy 129Sv mice. A) Representative Toluidine-blue stained micrographs of vascular perfused-fixed healthy 129Sv lungs.

Suppl. Figure 3. Age-dependent analysis of tissue composition and connective-tissue protein gene expression in healthy $129 \mathrm{~Sv}$ mice. A) Masson-Goldner trichrome staining of lungs from healthy $129 \mathrm{~Sv}$ mice at (left to right top panel) 10, 20, 30, and 40, 50 and 60 weeks of age (left to right bottom panel); B) hydroxyproline level was quantified in representative tissue sections at 40, 50 and 60 weeks (n=5). RTPCR gene expression analysis of: C) collagen 1a1; D) collagen 2a1; E) collagen 3a1; F) elastin; and G) fibronectin in healthy 129Sv lungs at ages of 10-60 weeks in lung tissue. Gene expression of all investigated genes significantly decreased from week 10 to week 30-40, where after gene expression tended to increase. Minimum gene expression was continuously found at week 40 . Normalized by Gapdh; +p<0.05 vs. 10 weeks; \#p<0.05 vs. 20 weeks, $\$ p<0.05$ vs. 30 weeks. $<p<0.05$ vs. 40 weeks.

Suppl. Figure 4. Age-dependent analysis of BALF cells in healthy 129/Sv mice. B) relative quantification of leukocyte subpopulations in BALF cells of healthy 129Sv mice.

Suppl. Figure 5. Age-dependent analysis of expression of genes related to the cholesterol metabolism in healthy $\mathbf{1 2 9} / \mathrm{Sv}$ mice. A) RT-PCR gene expression analysis of ATP binding cassette A1 (Abca1), ATP binding cassette G1 (Abcg1), cholesterol-25-hydroxylase (Ch25h), LDL receptor $(L d l r)$, liver X receptor alpha $(L x r a)$, sterol response element binding protein 2 (Srebp2) and chitinase like $3(Y m 1)$ in BALF cells. Expression of Abcg1, Ch25h and Srebp2 turned to significantly decrease from week 30 to week 40 . Normalized by Gapdh. $+\mathrm{p}<0.05$ vs. 10 weeks; \#p<0.05 vs. 20 weeks, $\$ \mathrm{p}<0.05$ vs. 30 weeks. $<\mathrm{p}<0.05$ vs. 40 weeks. 


\section{Supplementary Tables}

Suppl. Table 1. Determined stereological parameters.

\begin{tabular}{|c|c|c|}
\hline Parameter & Determination & Magnification \\
\hline Lung volume $\mathrm{V}$ [ml] & Fluid displacement & \\
\hline V (par,lung) [ml] & Point counting & $\mathrm{x} 5$ \\
\hline V (vent-par,lung) [ml] & Point counting & $\mathrm{x} 5$ \\
\hline $\mathrm{V}$ (non-vent-par, lung) [ml] & Point counting & $x 5$ \\
\hline Vv (vent-par/par) & Point counting & $x 5$ \\
\hline Vv (non-vent-par/par) & Point counting & $x 5$ \\
\hline Vv (par/lung) & Point counting & $x 5$ \\
\hline V (alv,lung) [ml] & Point counting & $x 20$ \\
\hline V (duct, lung) [ml] & Point counting & $x 20$ \\
\hline V (sept, lung) [ml] & Point counting & $\mathrm{x} 20$ \\
\hline S (alvepi, vent-par) [cm2] & Intersection counting & $\mathrm{x} 20$ \\
\hline Septal thickness $[\mu \mathrm{m}]$ & $\mathrm{V}$ (sept, lung) $* 2 / \mathrm{S}$ (alvepi, vent-par) & $\mathrm{x} 20$ \\
\hline Mean linear intercept $[\mu \mathrm{m}]$ & Intersection counting & $x 20$ \\
\hline PSI (alv) $[\mu \mathrm{m}]$ & $\begin{array}{l}\text { Random-ruler mediated length } \\
\text { assessment }\end{array}$ & $x 20$ \\
\hline $\bar{v}_{\mathrm{v}}(\mathrm{alv})\left[\mu \mathrm{m}^{3}\right]$ & $\pi / 3^{*}$ PSI $(\mathrm{alv})^{3}$ & $x 20$ \\
\hline
\end{tabular}


Suppl. Table 2. List of primers used for RT-PCR.

\begin{tabular}{|c|c|c|c|c|}
\hline Gene & Protein & Forward primer & Reverse primer & $\begin{array}{l}\text { Accession } \\
\text { number }\end{array}$ \\
\hline Gapdh & GAPDH & ATGACTCCACTCACGGCAAA & ATGTTAGTGGGGTCTCGCTC & NM_001289726.1 \\
\hline Fn & $\begin{array}{c}\text { Fibronecti } \\
\mathrm{n}\end{array}$ & CCAGAGGAGGCACAAGGTTC & ATGGCGTAATGGGAAACCGT & NM_010233.2 \\
\hline Eln & Elastin & TCACCACCССACСТCTTTGT & CCAAAGAGCACACCAACAATCAA & NM_007925.4 \\
\hline Col1a1 & Collagen I & GAG GTG ATG CTG GTC CCA A & AGC TTC ACC CTT GTC ACC A & NM_007742.3 \\
\hline Col1a2 & Collagen I & $\begin{array}{c}\text { GAA CTG GAG AAA CAG GTG } \\
\text { CA }\end{array}$ & GAG CAC CAA GAA GAC CCT GA & NM_007743.2 \\
\hline Col3a1 & $\begin{array}{c}\text { Collagen } \\
\text { III }\end{array}$ & $\begin{array}{c}\text { GTG ACA AAG GTG AAA CTG } \\
\text { GTG A }\end{array}$ & TAC CAA TTG CAC CCT GGT GA & NM_009930.2 \\
\hline Abca1 & ABCA1 & GCGACCATGAAAGTGACACG & CAGCACATAGGTCAGCTCGT & NM_013454.3 \\
\hline Abcg1 & ABCG1 & GGATTTCATCGTCCTGGGCA & TGGCTTGGAGGCGGTTTTTA & NM_009593.2 \\
\hline Ch25h & $\begin{array}{c}\text { Cholester } \\
\text { ol-25- } \\
\text { hydroxyla } \\
\text { se }\end{array}$ & CGTCCAGCTCCTAAGTCACG & AGGACGAGTTCTGGTGATGC & NM_009890.1 \\
\hline Chil3 & YM1 & $\begin{array}{c}\text { GTG GAG CCT AAG GAA GAG } \\
\text { GC }\end{array}$ & GAC CGC AAA GCC TGT CAG T & NM_007695.3 \\
\hline Ldlr & $\begin{array}{l}\text { LDL- } \\
\text { receptor }\end{array}$ & TCAGTGCCAATCGACTCACG & GTCTCACACCAGTTCACCCC & NM_010700.3 \\
\hline Nr1h3 & $\mathrm{LXR} \alpha$ & CAGGTTGGGTGTTTTCTGGC & GAAGAACCCTGCACAAAGTGG & NM_001177730.1 \\
\hline Srebp2 & SREBP & TGATGATCACCCCGACGTTC & GTCACGAGGCTTTGCACTTG & NM_033218.1 \\
\hline Lpla2 & LPLA2 & ACCCCAGCAAGAGGAATGTG & CCGTTTTCATTTGGGGCTCG & NM_133792.2 \\
\hline Lipa & LAL & CCACCAAGTAGGTGTAGGCAC & TGCATCTTCCGGGAGTGGT & NM_021460.3 \\
\hline Dhcr24 & DHCR24 & GATGAATGGTCAACGCGAGC & TTTGGGTGACACAGGTTGCT & NM_053272.2 \\
\hline Cd36 & CD36 & ATGAATGGTTGAGACCCCGTG & GATTGGCTTCAGGGAGACTGT & NM_001159558.1 \\
\hline Сур27a1 & CYP27A1 & GGTCGGAGGATTGCAGAACT & GGTCGGAGGATTGCAGAACT & NM_024264.5 \\
\hline Npc1 & NPC1 & AAAGGCAACGTGTTCTTCACAG & GTTAAAACCCATGAGCGTTGTCT & NM_008720.2 \\
\hline Npc2 & NPC2 & CATTGTCCCCCGAGATAGCC & CCATCCTGTCTGGTGGAACC & NM_023409.4 \\
\hline Hmgcr & HMGCR & TTGGAGTTGGCACCATGTCA & CTCTAGGACCAGCGACACAC & NM_008255.2 \\
\hline Pparg & PPAR $\gamma$ & $\begin{array}{c}\text { CGGTGAACCACTGATATTCAGG } \\
\text { A }\end{array}$ & GGTCCACAGAGCTGATTCCG & NM_001127330.2 \\
\hline Msr1 & SRA1 & ССТTTCACCTCTGGACAAGTCA & ATGTCAATGGAGGCCCCAAC & NM_031195.2 \\
\hline Nr1h2 & $\operatorname{LXR} \beta$ & CTCGGTCCAGGAGATTGTGG & CTGTCTCGTGGTTGTAGCGT & NM_001285518.1 \\
\hline
\end{tabular}


Suppl. Table 3. Mixed-effects model to differentiate the potential contibution of the genotype (group) versus time in the changes of different parameters measured.

\begin{tabular}{|c|c|c|}
\hline & \multicolumn{2}{|c|}{ p-value } \\
\hline Parameter & Group (Control vs KO) & Time (weeks) \\
\hline BW & 0.0042 & $<0.0001$ \\
\hline Lung volume & 0.0005 & $<0.0001$ \\
\hline IC & $<0.0001$ & $<0.0001$ \\
\hline Cst & $<0.0001$ & $<0.0001$ \\
\hline H PEEP 1 $\mathrm{cmH}_{2} \mathrm{O}$ & $<0.0001$ & $<0.0001$ \\
\hline $\mathrm{H}$ PEEP 3 $\mathrm{cmH}_{2} \mathrm{O}$ & $<0.0001$ & $<0.0001$ \\
\hline $\mathrm{H} \mathrm{PEEP} \mathrm{cmH}_{2} \mathrm{O}$ & $<0.0001$ & $<0.0001$ \\
\hline $\mathrm{G}$ & 0.0010 & $<0.0001$ \\
\hline Eta & $\mathrm{ns}$ & 0.0031 \\
\hline Vv(vent-par/par) & 0.0004 & $\mathrm{~ns}$ \\
\hline Vv(non-vent-par/par) & 0.0003 & $\mathrm{~ns}$ \\
\hline Vv (alv/par) & $<0.0001$ & 0.0159 \\
\hline Vv(duct/par) & $<0.0001$ & 0.0023 \\
\hline MLI & $\mathrm{ns}$ & 0.0032 \\
\hline $\mathrm{S}($ alvepi) & $<0.0001$ & $<0.0001$ \\
\hline Septal thickness & 0.0338 & 0.0005 \\
\hline Total BAL cells & $<0.0001$ & $\mathrm{~ns}$ \\
\hline Total cholesterol & $\mathrm{ns}$ & $<0.0001$ \\
\hline SpO & $<0.0001$ & $\mathrm{~ns}$ \\
\hline
\end{tabular}


Suppl. Table 4. Age related changes in lung morphometry in healthy 129Sv mice. Absolute stereological lung volumes are given with mean and standard deviation (SD) for every age group. $\mathrm{V}($ par,lung $)=$ absolute lung parenchyma volume; $\mathrm{V}$ (non-par,lung $)$ = absolute non-parenchyma volume; $\mathrm{V}($ vent-par,lung $)$ = absolute ventilated parenchyma volume; V(non-vent-par,lung) = absolute nonventilated parenchyma volume; $\mathrm{V}(\mathrm{alv}, \mathrm{lung})=$ absolute alveolar space volume; $\mathrm{V}(\mathrm{duct}, \mathrm{lung})=$ Absolute ductal airspace volume; $\mathrm{V}($ sept,lung $)$ = absolute alveolar septum volume.

\begin{tabular}{|c|c|c|c|c|c|c|c|c|c|c|c|c|}
\hline & \multicolumn{2}{|c|}{10 weeks } & \multicolumn{2}{c|}{20 weeks } & \multicolumn{2}{|c|}{30 weeks } & \multicolumn{2}{|c|}{40 weeks } & \multicolumn{2}{|c|}{50 weeks } & \multicolumn{2}{c|}{60 weeks } \\
\hline Parameter[ml] & Mean & SD & Mean & SD & Mean & SD & Mean & SD & Mean & SD & Mean & SD \\
\hline V(par,lung) & 0.47 & 0.07 & 0.54 & 0.05 & 0.66 & 0.08 & 0.46 & 0.05 & 0.56 & 0.03 & 0.55 & 0.09 \\
\hline V(non-par,lung) & 0.06 & 0.02 & 0.08 & 0.03 & 0.10 & 0.02 & 0.08 & 0.02 & 0.09 & 0.03 & 0.07 & 0.01 \\
\hline V(vent-par,lung) & 0.46 & 0.07 & 0.53 & 0.05 & 0.66 & 0.09 & 0.46 & 0.05 & 0.56 & 0.03 & 0.54 & 0.09 \\
\hline $\begin{array}{c}\text { V(non-vent- } \\
\text { par,lung) }\end{array}$ & 0.01 & 0.01 & 0.01 & 0.00 & 0.01 & 0.01 & 0.00 & 0.00 & 0.00 & 0.00 & 0.00 & 0.00 \\
\hline V(alv,lung) & 0.24 & 0.04 & 0.27 & 0.03 & 0.35 & 0.04 & 0.22 & 0.03 & 0.28 & 0.02 & 0.25 & 0.05 \\
\hline V(duct,lung) & 0.16 & 0.03 & 0.20 & 0.02 & 0.25 & 0.05 & 0.20 & 0.03 & 0.23 & 0.05 & 0.24 & 0.05 \\
\hline V(sept,lung) & 0.05 & 0.01 & 0.06 & 0.01 & 0.06 & 0.02 & 0.04 & 0.01 & 0.05 & 0.01 & 0.06 & 0.01 \\
\hline
\end{tabular}


A

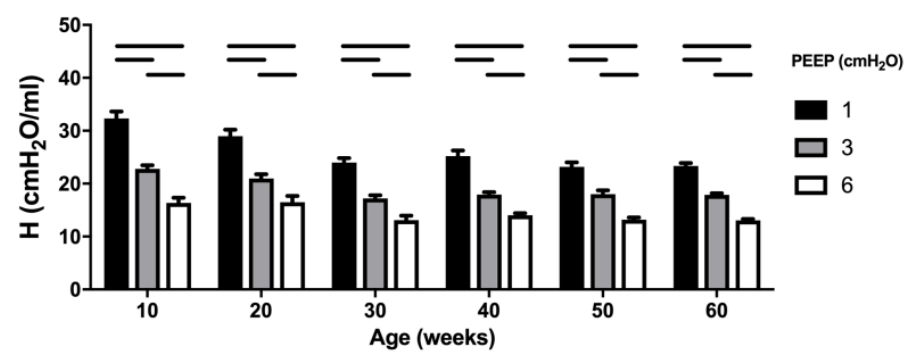

Suppl. Figure 1 Age related changes in lung mechanics in healthy $129 \mathrm{~Sv}$ mice. E) Tissue elastance at PEEP $1 \mathrm{cmH} 2 \mathrm{O}$ (black), $3 \mathrm{cmH} 2 \mathrm{O}$ (grey) and $6 \mathrm{cmH} 2 \mathrm{O}$ (white); Mean $\pm \mathrm{SD}, \mathrm{n} \geq 5$.

$209 \times 297 \mathrm{~mm}(300 \times 300$ DPI $)$ 


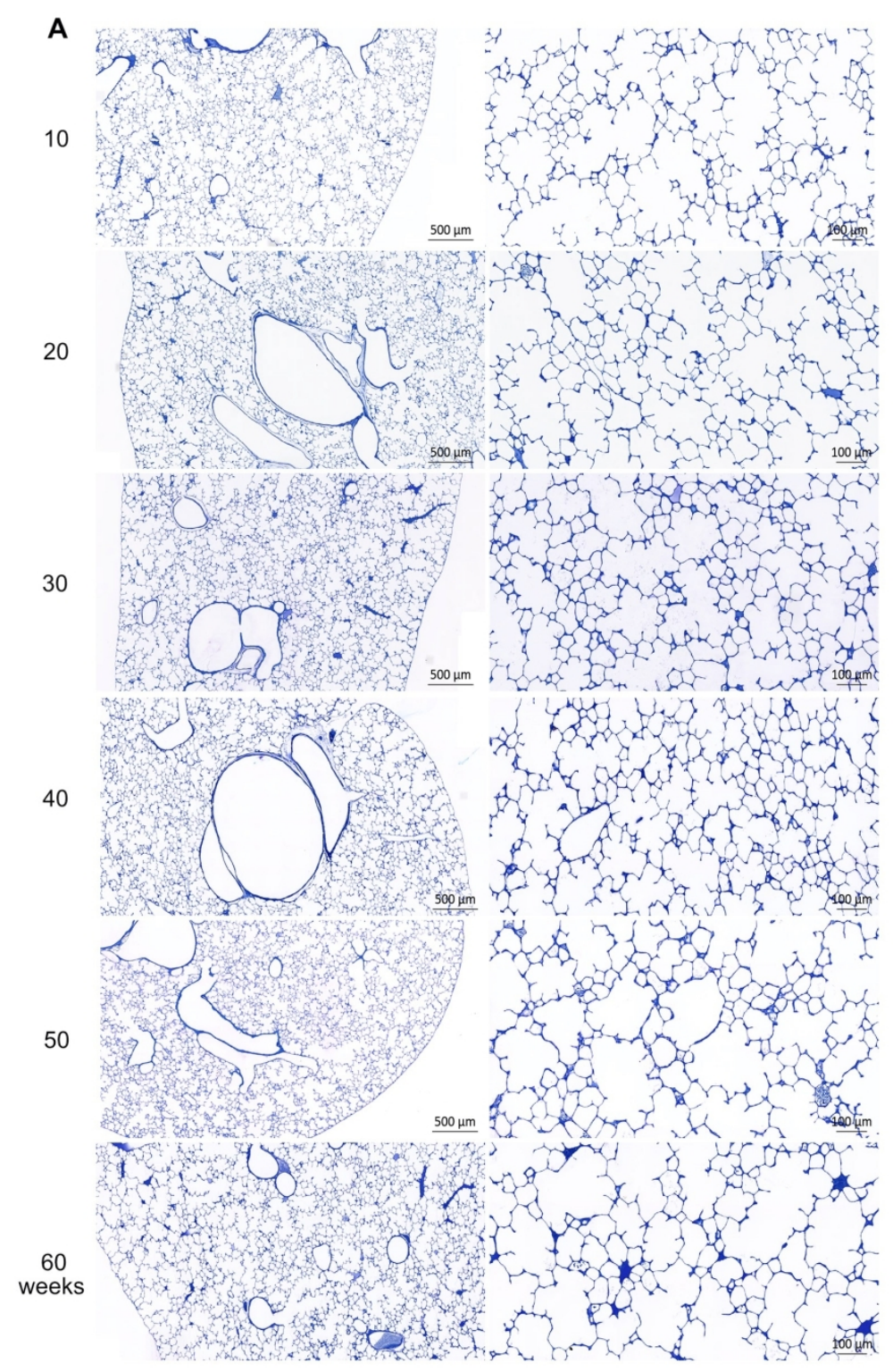

Suppl. Figure 2. Age related changes in lung morphology in healthy 129 Sv mice. A) Representative Toluidine-blue stained micrographs of vascular perfused-fixed healthy $129 \mathrm{~Sv}$ lungs.

$139 \times 209 \mathrm{~mm}(300 \times 300 \mathrm{DPI})$ 

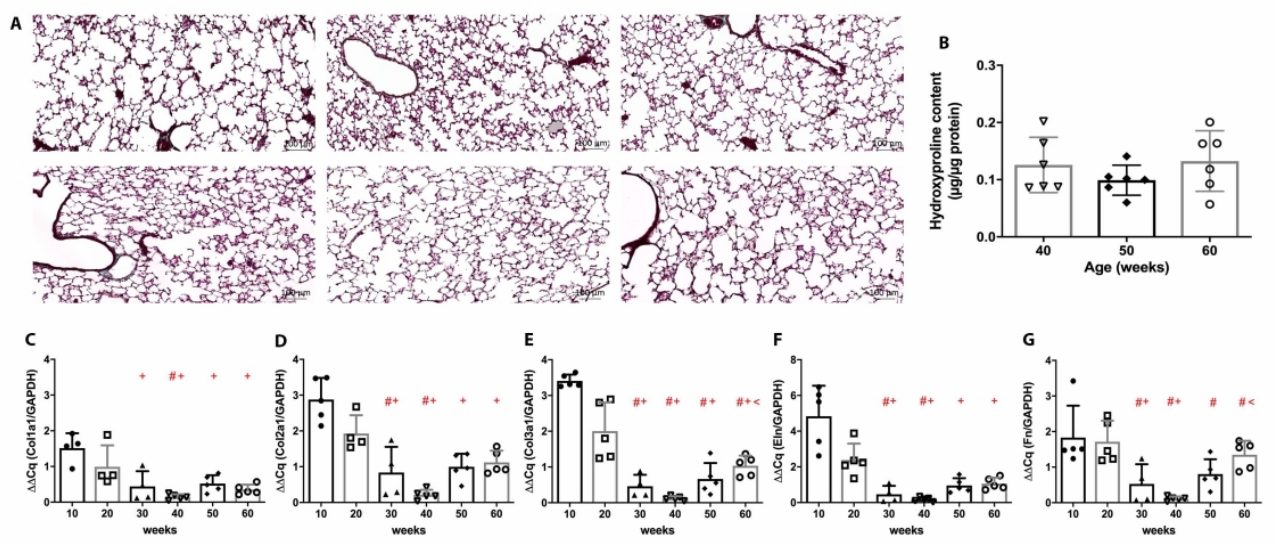

Suppl. Figure 3. Age-dependent analysis of tissue composition and connective-tissue protein gene expression in healthy 129Sv mice. A) Masson-Goldner trichrome staining of lungs from healthy $1295 \mathrm{v}$ mice at (left to right top panel) 10, 20, 30, and 40, 50 and 60 weeks of age (left to right bottom panel); B) hydroxyproline level was quantified in representative tissue sections at 40, 50 and 60 weeks $(n=5)$. RT-PCR gene expression analysis of: C) collagen $1 \mathrm{a} 1$; D) collagen $2 \mathrm{a} 1$; E) collagen $3 \mathrm{a} 1$; F) elastin; and G) fibronectin in healthy $129 \mathrm{~Sv}$ lungs at ages of 10-60 weeks in lung tissue. Gene expression of all investigated genes significantly decreased from week 10 to week 30-40, where after gene expression tended to increase.

Minimum gene expression was continuously found at week 40 . Normalized by Gapdh; $+p<0.05$ vs. 10 weeks; \#p<0.05 vs. 20 weeks, §p<0.05 vs. 30 weeks. $<p<0.05$ vs. 40 weeks.

297×160mm (300 x 300 DPI) 


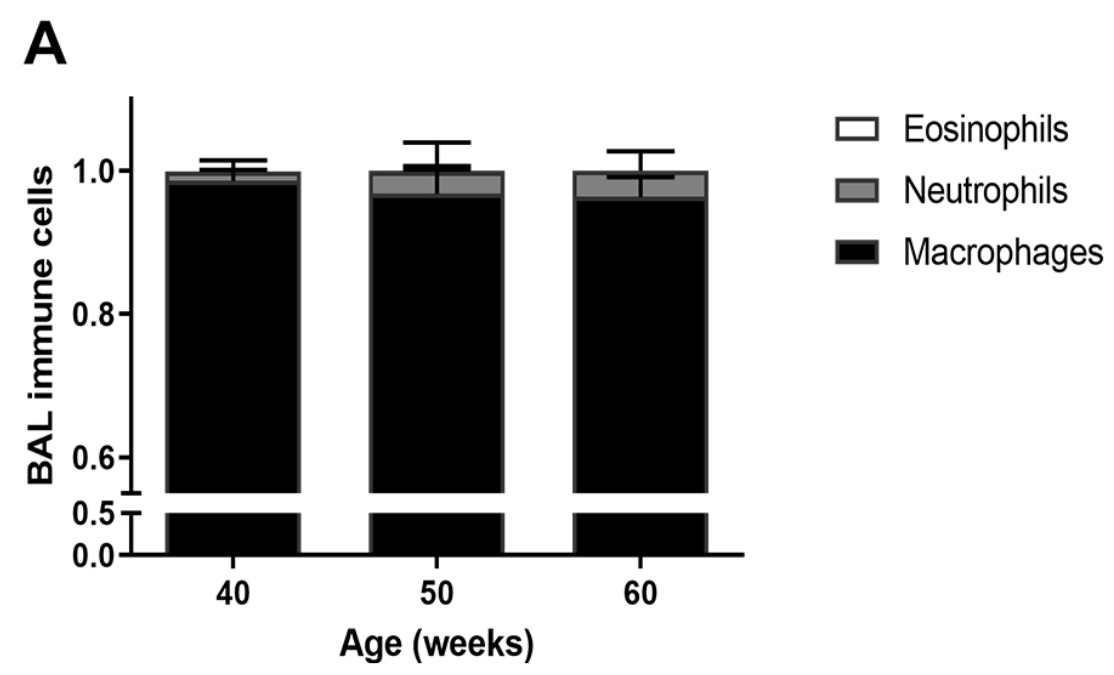

Suppl. Figure 4. Age-dependent analysis of BALF cells in healthy 129/Sv mice. B) relative quantification of leukocyte subpopulations in BALF cells of healthy $129 \mathrm{~Sv}$ mice.

$90 \times 52 \mathrm{~mm}(300 \times 300 \mathrm{DPI})$ 
A
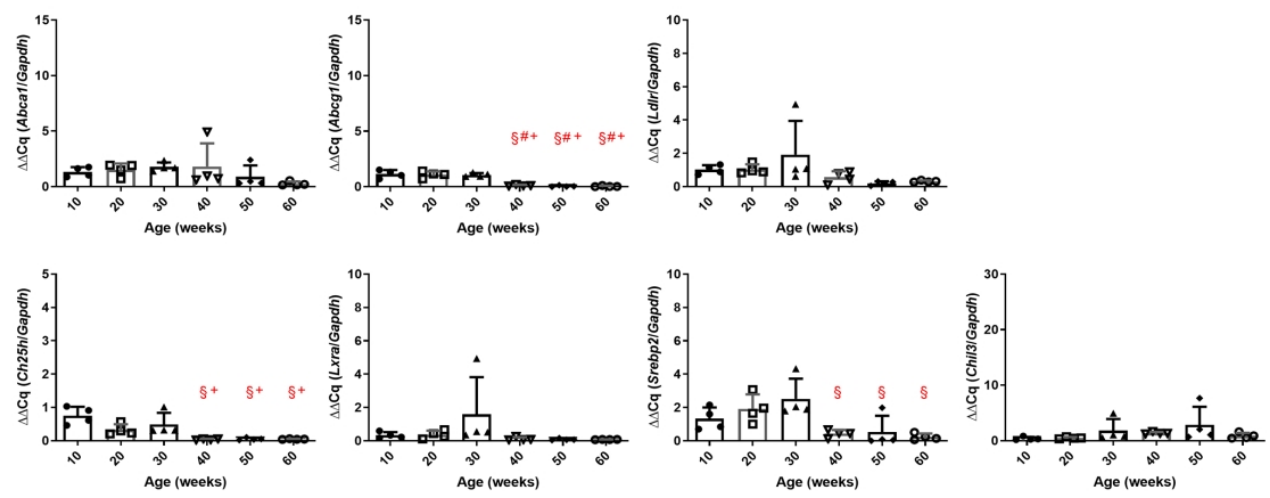

Suppl. Figure 5. Age-dependent analysis of expression of genes related to the cholesterol metabolism in healthy 129/Sv mice. A) RT-PCR gene expression analysis of ATP binding cassette A1 (Abca1), ATP binding cassette G1 (Abcg1), cholesterol-25-hydroxylase (Ch25h), LDL receptor (Ldlr), liver X receptor alpha (Lxra), sterol response element binding protein 2 (Srebp2) and chitinase like 3 (Ym1) in BALF cells. Expression of Abcg1, Ch25h and Srebp2 turned to significantly decrease from week 30 to week 40. Normalized by Gapdh. $+p<0.05$ vs. 10 weeks; $\# p<0.05$ vs. 20 weeks, $\S p<0.05$ vs. 30 weeks. $<p<0.05$ vs. 40 weeks.

$209 \times 99 \mathrm{~mm}(300 \times 300$ DPI $)$ 